\title{
Gall-ID: tools for genotyping gall-causing phytopathogenic bacteria
}

Edward W Davis II, Alexandra J Weisberg, Javier F Tabima, Niklaus J. Grunwald, Jeff Chang

Understanding the population structure and genetic diversity of plant pathogens, as well as the effect of agricultural practices on pathogen evolution, are important for disease management. Developments in molecular methods have contributed to increase the resolution for accurate pathogen identification but those based on analysis of DNA sequences can be less straightforward to use. To address this, we developed Gall-ID, a web-based platform that uses DNA sequence information from 16S rDNA, multilocus sequence analysis and whole genome sequences to group disease-associated bacteria to their taxonomic units. Gall-ID was developed with a particular focus on gall-forming bacteria belonging to Agrobacterium, Pseudomonas savastanoi, Pantoea agglomerans, and Rhodococcus. Members of these groups of bacteria cause growth deformation of plants, and some are capable of infecting many species of field, orchard, and nursery crops. GallID also enables the use of high-throughput sequencing reads to search for evidence for homologs of characterized virulence genes, and provides downloadable software pipelines for automating multilocus sequence analysis, analyzing genome sequences for average nucleotide identity, and constructing core genome phylogenies. Lastly, additional databases were included in Gall-ID to help determine the identity of other plant pathogenic bacteria that may be in microbial communities associated with galls or causative agents in other diseased tissues of plants. The URL for Gall-ID is http://gall-id.cgrb.oregonstate.edu/. 
1

2

3

4

5

6

7

8

9

14

15

16

17

18

\section{Gall-ID: tools for genotyping gall-causing phytopathogenic bacteria}

Edward W. Davis II $^{1,2^{*}}$, Alexandra J. Weisberg ${ }^{1 *}$, Javier F. Tabima ${ }^{1}$, Niklaus J. Grünwald ${ }^{1,2,3,4}$, and Jeff $\mathrm{H}$. Chang ${ }^{1,2,4}$

${ }^{1}$ Department of Botany and Plant Pathology, Oregon State University, Corvallis, OR, 97331, USA

${ }^{2}$ Molecular and Cellular Biology Program, Oregon State University, Corvallis, OR, 97331, USA

${ }^{3}$ Horticultural Crops Research Laboratory, USDA-ARS, Corvallis, OR, 97331, USA

${ }^{4}$ Center for Genome Research and Biocomputing, Oregon State University, Corvallis, OR, 97331, USA

*Equal contribution

Corresponding author

Jeff H. Chang

3096 Cordley Hall, Corvallis, OR, USA

changj@science.oregonstate.edu 


\section{ABSTRACT}

Understanding the population structure and genetic diversity of plant pathogens, as well

21 as the effect of agricultural practices on pathogen evolution, are important for disease

22 management. Developments in molecular methods have contributed to increase the resolution for

23 accurate pathogen identification but those based on analysis of DNA sequences can be less

24 straightforward to use. To address this, we developed Gall-ID, a web-based platform that uses

25 DNA sequence information from 16S rDNA, multilocus sequence analysis and whole genome

26 sequences to group disease-associated bacteria to their taxonomic units. Gall-ID was developed

27 with a particular focus on gall-forming bacteria belonging to Agrobacterium, Pseudomonas

28 savastanoi, Pantoea agglomerans, and Rhodococcus. Members of these groups of bacteria cause

29 growth deformation of plants, and some are capable of infecting many species of field, orchard,

30 and nursery crops. Gall-ID also enables the use of high-throughput sequencing reads to search

31 for evidence for homologs of characterized virulence genes, and provides downloadable software

32 pipelines for automating multilocus sequence analysis, analyzing genome sequences for average

33 nucleotide identity, and constructing core genome phylogenies. Lastly, additional databases were

34 included in Gall-ID to help determine the identity of other plant pathogenic bacteria that may be

35 in microbial communities associated with galls or causative agents in other diseased tissues of

36 plants. The URL for Gall-ID is http://gall-id.cgrb.oregonstate.edu/. 


\section{INTRODUCTION}

\section{Diagnostics}

Determining the identity of the disease causing pathogen, establishing its source of

introduction, and/or understanding the genetic diversity of pathogen populations are critical steps

for containment and treatment of disease. Proven methods for identification have been developed based on discriminative phenotypic and genotypic characteristics, including presence of antigens, differences in metabolism, or fatty acid methyl esters, and assaying based on polymorphic nucleotide sequences (Alvarez 2004). For the latter, polymerase chain reaction (PCR) amplification-based approaches for amplifying informative regions of the genome can be used. These regions should have broadly conserved sequences that can be targeted for amplification but the intervening sequences need to provide sufficient resolution to infer taxonomic grouping. The 16S rDNA sequence is commonly used for identification (Stackebrandt \& Goebel 1994). Because of highly conserved regions in the gene sequence, a single pair of degenerate oligonucleotide primers can be used to amplify the gene from a diversity of bacteria, and allow for a kingdom-wide comparison. In general, the sequences of the amplified fragments have enough informative polymorphic sites to delineate genera, but do not typically allow for more refined taxonomic inferences at the sub-genus level (Janda \& Abbott 2007). Multilocus sequence analysis (MLSA) leverages the phylogenetic signal from four to ten genes to provide increased resolution, and can distinguish between species and sometimes sub-species (Wertz et al. 2003; Zeigler 2003). MLSA however, is more restricted than the use of 16S rDNA sequences and may not allow for comparisons between members of different genera. MLSA also requires more time 
61 and effort to identify informative and taxon-specific genes as well as develop corresponding

62 oligonucleotide primer sets.

63 Whole genome sequences can also be used. This is practical because of advances in next

64 generation sequencing technologies. The key advantages of this approach is that availability of

65 whole genome sequences obviates the dependency on a priori knowledge to provide clues on

66 taxonomic association of a pathogen and the need to select and amplify marker genes. Also,

67 whole genome sequences provide the greatest resolution in terms of phylogenetic signal, and

68 sequences that violate assumptions of phylogenetic analyses (e.g., not vertically inherited) can be

69 removed from studies to allow for robust analyses. Briefly, sequencing reads of genome(s) are

70 compared to a high quality draft or finished reference genome sequence to identify variable

71 positions between the genome sequences (Pearson et al. 2009). The positions core to the

72 compared genome sequences are aligned and used to generate a phylogenetic tree. Alternatively,

73 whole genome sequences can be used to determine average nucleotide identities (ANI) between

74 any sufficiently similar pair, e.g., within the same taxonomic family, of genome sequences to

75 determine genetic relatedness (Goris et al. 2007; Kim et al. 2014). ANI can be used to make

76 taxonomic inferences, as a $95 \%$ threshold for ANI has been calibrated to those used to

77 operationally define bacterial species based on 16S rDNA ( $>94 \%$ similarity) and DNA-DNA

78 hybridization (DDH; 70\%) (Goris et al. 2007). Finally, the whole genome sequences can be

79 analyzed to inform on more than just the identity of the causative agent and provide insights into

80 mechanisms and evolution of virulence. However, a non-trivial trade-off is that processing,

81 storing, and analyzing whole genome sequence data sets require familiarity with methods in

82 computational biology. 


\section{Agrobacterium spp.}

Members from several taxa of Gram-negative bacteria are capable of causing abnormal

growth of plants. Members of Agrobacterium are the most notorious causative agents of

87 deformation of plant growth. These bacteria have been classified according to various schemes

that differ in the phenotypic and genetic characteristics that were used. Its taxonomic

classification has been a subject of multiple studies (Young et al. 2001; Farrand et al. 2003;

Young 2003). Here, we will use the classification scheme that is based on disease phenotype and

more commonly encountered in the literature. Within Agrobacterium there are four recognized

groups of gall-causing bacteria. A. tumefaciens (also known as Rhizobium radiobacter (Young et

al. 2001), formerly A. radiobacter, genomovar G8 forms A. fabrum (Lassalle et al. 2011)) can

cause crown gall disease that typically manifests as tumors on roots or stem tissue (Gloyer 1934;

Kado 2014). A. tumefaciens can infect a wide variety of hosts and the galls can restrict plant

growth and in some cases kill the plant (Gloyer 1934; Schroth 1988). Other gall causing clades

include $A$. vitis (restricted to infection of grapevine), A. rubi (Rubus galls), and A. larrymoorei,

which is sufficiently different based on results of DNA-DNA hybridization studies to justify a

species designation (Hildebrand 1940; Ophel \& Kerr 1990; Bouzar \& Jones 2001). The genus

was also traditionally recognized to include hairy-root inducing bacteria belonging to $A$.

rhizogenes, as well as non-pathogenic biocontrol isolates belonging to $A$. radiobacter (Young et

genomes, which in some cases include a linear replicon (Allardet-Servent et al. 1993).

A Ti (tumor-inducing) plasmid imparts upon members of Agrobacterium the ability to 
107 and integrated into the genome of the host cell (Van Larebeke et al. 1974; Chilton et al. 1977;

108 Thompson et al. 1988; Ward et al. 1988; Broothaerts et al. 2005). Conjugation is mediated by a

109 type IV secretion system, encoded by genes located outside the borders of the T-DNA on the Ti

110 plasmid (Thompson et al. 1988). Within the T-DNA are key genes that encode for auxin,

111 cytokinin, and opine biosynthesis (Morris 1986; Binns \& Costantino 1998). Expression of the

112 former two genes in the plant leads to an increase in plant hormone levels to cause growth

113 deformation whereas the latter set of genes encode enzymes for the synthesis of modified sugars

114 that only organisms with the corresponding opine catabolism genes can use as an energy source

115 (Bomhoff et al. 1976; Montoya et al. 1977). The latter genes are located outside the T-DNA

116 borders on the Ti plasmid (Zhu et al. 2000).

117

118 Pseudomonas savastanoi

119 Pseudomonas savastanoi (formerly Pseudomonas syringae pv. savastanoi, (Gardan et al.

120 1992)) is the causal agent of olive knot disease, typically forming as aerial tumors on stems and

121 branches. Phytopathogenicity of $P$. savastanoi is dependent on the $h r p / h r c$ genes located in a

122 pathogenicity island on the chromosome (Sisto et al. 2004). These genes encode for a type III

123 secretion system, a molecular syringe that injects type III effector proteins into host cells that

124 collectively function to dampen host immunity (Chang et al. 2014). Phytopathogenicity of $P$.

125 savastanoi is also associated with the production of phytohormones. Indole-3-acetic acid may

126 have an indirect role as a bacterial signaling molecule (Aragon et al. 2014). A cytokinin

127 biosynthesis gene has also been identified on plasmids in P. savastanoi and strains cured of the

128 plasmid caused smaller galls but were not affected in growth within the galls (Iacobellis et al.

129 1994; Bardaji et al. 2011). 


\section{Pantoea agglomerans}

132 Pantoea agglomerans (formerly Erwinia herbicola) is a member of the

133 Enterobacteriaceae family. P. agglomerans can induce the formation of galls on diverse species

134 of plants (Cooksey 1986; Burr et al. 1991; Opgenorth et al. 1994; DeYoung et al. 1998;

135 Vasanthakumar \& McManus 2004). Phytopathogenicity is dependent on the pPATH plasmid

136 (Manulis \& Barash 2003; Weinthal et al. 2007). This plasmid contains a pathogenicity island

137 consisting of an $h r p / h r c$ cluster and operons encoding for the biosynthesis of cytokinins, indole-

138 3-acetic acid, and type III effectors (Clark et al. 1993; Lichter et al. 1995; Nizan et al. 1997; Mor

139 et al. 2001; Nizan-Koren et al. 2003; Barash \& Manulis 2005; Barash et al. 2005; Barash \&

140 Manulis-Sasson 2007). As is the case with $P$. savastanoi, mutants of the $h r p / h r c$ genes abolish

141 pathogenicity whereas mutations in the phytohormone biosynthesis genes led to galls of reduced

142 size (Manulis et al. 1998; Mor et al. 2001; Nizan-Koren et al. 2003; Barash \& Manulis-Sasson 143 2007).

145 Rhodococcus spp.

146 Gram-positive bacteria within the Rhodococcus genus can cause leafy gall disease to over

147100 species of plants (Putnam \& Miller 2007). The phytopathogenic members of this genus

148 belong to at least two genetically distinct groups of bacteria, with $R$. fascians (formerly

149 Corynebacterium fascians) being the original recognized species (Goodfellow 1984; Creason et

150 al. 2014a). It is suggested that $R$. fascians upsets levels of phytohormones of the plant to induce

151 gall formation. However, unlike Ti plasmid-carrying Agrobacterium, it is hypothesized that $R$.

152 fascians directly synthesizes and secretes the cytokinin phytohormone (Stes et al. 2013; Creason 
153 et al. 2014b). Phytopathogenicity is most often associated with a linear plasmid, which carries a

154 cluster of virulence loci, att, fasR, and fas (Creason et al. 2014b). The functions for the translated

155 products of att are unknown but the sequences have homology to proteins involved in amino acid

156 and antibiotic biosynthesis (Maes et al. 2001). The fasR gene is necessary for full virulence; the

157 gene encodes a putative transcriptional regulator (Temmerman et al. 2000). Some of the genes

158 within the fas operon are necessary for virulence, as many of the fas genes encode proteins with

159 demonstrable functions in cytokinin metabolism (Crespi et al. 1992). In rare cases, the virulence

160 loci, or variants therein, are located on the chromosome (Creason et al. 2014b).

161 We developed Gall-ID to aid in determining the genetic identity of gall-causing members

162 of Agrobacterium, Pseudomonas, Pantoea, and Rhodococcus. Users can provide sequences from

163 16S rDNA or gene sets used in MLSA, and Gall-ID will automatically query curated databases

164 and generate phylogenetic trees to group the query isolate of interest and provide estimates of

165 relatedness to previously characterized species and/or genotypes. Users can also submit short

166 reads from whole genome sequencing projects to query curated databases to search for evidence

167 for known virulence genes of these gall-causing bacteria. Finally, users can download tools that

168 automate the analysis of whole genome sequencing data to infer genetic relatedness based on

169 MLSA, average nucleotide identity (ANI), or single nucleotide polymorphisms (SNPs).

170

171 MATERIAL AND METHODS

\section{Website framework and bioinformatics tools}

173 The Gall-ID website and corresponding R shiny server backend are based on the

174 Microbe-ID platform (Tabima et al. 2016) but includes major additions and modifications: Auto

175 MLSA, Auto ANI, BLAST with MAFFT, and the WGS Pipeline. The MLSA framework 
176 website was extended to support building Neighbor-Joining trees using incomplete distance

177 matrices (NJ*) using the function njs() in the R package PHYLOCH (Paradis et al. 2004). The

178 MLSA framework was also modified to use the multiple sequence alignment program MAFFT

179 using the R package PHYLOCH (Katoh \& Toh 2008; Heibl 2013; Katoh \& Standley 2013). This

180 allows user-submitted sequences to be added to pre-existing sequence alignments using the

181 MAFFT "--add" function, to dramatically reduce the computational time required for analysis.

182 The server hosting the Gall-ID tools is running Centos Linux release 6.6, MAFFT version

183 7.221, SRST2 version 0.1.5, Bowtie 2 version 2.2.3, and Samtools version 0.1.18. Gall-ID uses

184 R version 3.1.2 with the following R packages: Poppr version 1.1.0.99 (Kamvar et al. 2014), Ape

185 version 3.1-1 (Paradis et al. 2004), PHYLOCH version 1.5-5, and Shiny version 0.8.0.

186 The Auto MLSA tool was developed previously (Creason et al. 2014a). Briefly, Auto

187 MLSA does the following: BLAST (either TBLASTN or BLASTN) to query NCBI user-

188 selectable databases and/or local databases and retrieve sequences, filter out incomplete sets of

189 gene sequences, align gene sequence individually, concatenate aligned gene sequences,

190 determine the best substitution model (for amino acid sequences), filter out identical sequences,

191 append key information to sequences, and generate a partition file for RAxML (Stamatakis

192 2014). Auto MLSA also has the option of using Gblocks to trim alignments (Castresana 2000).

193 Auto MLSA was modified to use the NCBI E-utilities, implemented in BioPerl, to associate

194 accession numbers with taxon IDs, species names, and assembly IDs (Stajich 2002). For

195 organisms without taxon identifiers, Auto MLSA will attempt to extract meaningful genus and

196 species information from the NCBI nucleotide entry. Gene sequences are linked together using

197 assembly IDs, which allows for genomes with multiple chromosomes to be compared, without

198 having to rely on potentially ambiguous organism names. When assembly IDs are unavailable, 
199 whole genome sequences are linked using the four letter WGS codes, and, as a last resort,

200 sequences will be associated using their nucleotide accession number. The disadvantage of using

201 the latter approach is that organisms with multiple replicons, each with its own accession

202 number, will be excluded from analysis. Auto MLSA is available for download from the Gall-ID

203 website. Detailed instructions for using the tools are provided.

204 The Auto ANI script automates the calculations of ANI for all pairwise combinations for 205 any number of input genome sequences. Each of the supplied genome sequences are chunked 206 into $1020 \mathrm{nt}$ fragments and used as queries in all possible reciprocal pairwise BLAST searches.

207 Parameters for genome chunk size, percent identity, and percent coverage have default values set 208 according to published guidelines but can be changed by the user (Goris et al. 2007; Creason et 209 al. 2014a). BLAST version 2.2.31+ was used with recommended settings and previously 210 described in Creason et al. (2014): -task blastn -dust no -xdrop_gap 150 - penalty -1 -reward 1 211 -gapopen 5 -gapextend 2 (Goris et al. 2007). BLAST hits above the user-specified cut-offs (30\% 212 identity, 70\% coverage, by default) are averaged to calculate the pairwise ANI values.

214 unsupported. Versions 2.2.28-2.2.30 of BLAST+ have an undocumented bug that prevents

215 efficient filtering using -max_hsps and -max_target_seqs and precludes their use in ANI

216 calculation. Hence BLAST 2.2.31+ is the preferred and recommended version.

217 Sequences downloaded from NCBI are linked using assembly IDs. All accession types

218 from NCBI are supported, assuming accession numbers are provided in the header line of the

219 FASTA file. Locally generated genome sequences are also supported, in FASTA format,

220 provided they follow the specified header format listed in the user guide. Alternatively, an 
221 auxiliary script is provided to rename headers within user-generated FASTA files to the 222 supported format.

223 The WGS Pipeline was written in bash shell script and Perl. Paired Illumina sequencing 224 reads located in the "reads" folder of the pipeline are processed in pairs. The program SMALT 225 (Ponstingl, 2013) is used to align reads to a reference genome and produce CIGAR format output 226 files (Ponstingl 2013). The SSAHA_pileup program converts the CIGAR format files into 227 individual pileup files (Ning et al. 2001). The pileup output is then combined with any additional 228 supplied pre-computed pileup files and used to produce a core alignment of sites shared by $90 \%$

229 of the represented isolates. The optional "remove_recombination.sh" script runs the program 230 Gubbins (Croucher et al. 2014) to remove sites identified as potentially acquired by 231 recombination. Finally, the program RAxML is used to produce a maximum-likelihood 232 phylogenetic tree with non-parametric bootstrap support (Stamatakis 2014). By default 20 233 maximum likelihood tree searches are performed, and the "autoMRE" criterion is used to 234 determine the number of non-parametric bootstrap replicates.

235 The WGS Pipeline test analysis was performed and benchmarked using 10 cores of a 236 cluster server running Centos Linux release 6.6 and containing four AMD Opteron ${ }^{\mathrm{TM}} 63762.3$

237 Ghz processors (64 cores total) and 512 GB of RAM (Table 2). The versions of the tools used in 238 tests of this pipeline were Perl version 5.10.1, SMALT version 0.7.6, SSAHA_pileup version 2390.6 , Gubbins version 1.1.2, and RAxML version 8.1.17. The default parameters for WGS 240 Pipeline were used (20 ML search trees, "autoMRE" cutoff for bootstrap replicates) with the 241 exception that the maximum-allowed percentage gaps in the Gubbins recombination analysis 242 was increased to $50 \%$ in order to retain strain D188. The WGS Pipeline scripts were also 
243 modified to not ask for user input on the command line in order to run in a Sun Grid Engine

244 (SGE) cluster environment.

245 Vir-Search uses the program SRST2, which employs Bowtie 2 and Samtools, with the "--

246 gene_db" function to align the reads to custom databases of the virulence genes ( $\mathrm{Li}$ et al. 2009;

247 Inouye et al. 2012; Langmead \& Salzberg 2012; Inouye et al. 2014). The identity of the virulence

248 genes that the reads input by the user align to, the read coverage and depth, and the name of the

249 strain corresponding to the most similar allele are parsed from the SRST2 output and reported to

250 the user as a static webpage. Users are emailed a link to results once the analysis is complete.

251 The submitted sequencing reads are deleted from the server immediately after completion, and

252 results are available only to those with a direct link to the results webpage.

253

254 Datasets

255

The 16S and MLSA gene sequences were downloaded from the genome sequences of the 256 following reference strains: Agrobacterium strain C58, Rhodococcus strain A44a, P. savastanoi pv. phaseolicola 1448A, and P. agglomerans strain LMAE-2, C. michiganensis subsp.

258 nebraskensis NCPPB 2581, D. dadantii strain 3937, P. atrosepticum strain 21A, $R$. solanacearum strain GMI1000, X. oryzae pv. oryzicola strain CFBP2286, and X. fastidiosa

260 subsp. fastidiosa GB514 (NCBI assembly ID: GCF_000092025.1, GCF_000760735.1, 261 GCF_000012205.1, GCF_000814075.1, GCF_000355695.1, GCF_000147055.1, GCF_000740965.1, GCF_000009125.1, GCF_001042735.1, and GCF_000148405.1, respectively). The gene sequences were used as input for the Auto MLSA tool in BLAST searches carried out against complete genome sequences in the NCBI non-redundant (nr) and

265 whole genome sequence (wgs) databases. The Auto MLSA parameters were: minimum query 
266 coverage of 50\% (90\% for the $16 \mathrm{~S}$ plant pathogen dataset) and e-value cutoffs of $1 \mathrm{e}-5$ for $\mathrm{nr}$ and

$2671 \mathrm{e}-50$ for wgs. BLAST searches were limited to the genus for the bacteria of interest, with the

268 exceptions of Agrobacterium, which was limited to Rhizobiaceae, and P. savastanoi, which was

269 limited to the P. syringae group. BLAST searches were completed in August of 2015. The Auto

270 MLSA tool uses MAFFT aligner to produce multiple sequence alignments for each gene (Katoh

271 \& Standley 2013). The Gblocks trimmed alignment output of Auto MLSA was not used because

272 Gall-ID aligns user-submitted gene sequences to each full gene alignment (Castresana 2000).

273

274 Bacterial strains, growth conditions, nucleic acid extraction, and genome sequencing

275 Cultures of Agrobacterium were grown overnight in Lysogeny Broth (LB) media at

$27628^{\circ} \mathrm{C}$, with shaking at $250 \mathrm{rpm}$ (Table 3). Cells were pelleted by centrifugation and total genomic

277 DNA was extracted using a DNeasy Blood and Tissue kit (Qiagen, Venlo, Netherlands). DNA

278 was quantified using a QuBit Fluorometer (Thermo Fisher, Eugene, Oregon) and libraries were

279 prepared using an Illumina Nextera XT DNA Library Prep kit, according to the instructions of

280 the manufacturer, with the exception that libraries were normalized based on measurements from

281 an Agilent 2100 Bioanalyzer (Agilent Technologies, Santa Clara, CA). Each library was

282 assigned an individual barcode using an Illumina Nextera XT Index kit. Libraries were

283 multiplexed and sequenced on an Illumina MiSeq to generate 300 bp paired-end reads.

284 Sequencing was done in the Center for Genome Research and Biocomputing Core Facility

285 (Oregon State University, Corvallis, OR). Sickle was used to trim reads based on quality

286 (minimum quality score cutoff of 25 , minimum read length $150 \mathrm{bp}$ after trimming) (Joshi \& Fass

287 2011). Read quality was assessed prior to and after trimming using FastQC (Andrews 2010).

288 Paired reads for each library were de novo assembled using Velvet version 1.2.10 with the short 
289 paired read input option (“-shortPaired"), estimated expected coverage (“-exp_cov auto"), and

290 default settings for other parameters (Zerbino \& Birney 2008). Genome sequences were

291 assembled using a range of input hash lengths (k-mer sizes), and the final assembly for each

292 isolate was identified based on those with the best metrics for the following parameters: total

293 assembly length (5.0 7.0 Mb), number of contigs, and N50. Paired reads for each library were

294 error corrected and assembled using SPAdes versions 3.6.2 and 3.7.0, with the careful option (“"-295 careful") and kmers 21, 33, 55, 77, and 99. Scaffolds shorter than 500bp and with coverage less

296 than 5X were removed from the SPAdes assemblies prior to analysis.

297

298

299

\section{RESULTS AND DISCUSSION}

Gall-ID (http://gall-id.cgrb.oregonstate.edu/) is based on the Microbe-ID platform and

uses molecular data to determine the identity of plant pathogenic bacteria (Tabima et al. 2016).

Gall-ID is organized into modules shown as tabs that allow users to choose from one of four options for analyzing data (Figure 1).

303

\section{Gall Isolate Typing}

The "Gall Isolate Typing" tab provides online tools to use molecular data, either 16S or

sequences of marker genes used for MLSA, to group isolates of interest into corresponding

taxonomic units that include gall-causing pathogens. Users must first select the appropriate

taxonomic group, Agrobacterium, Pseudomonas, Pantoea, or Rhodococcus for comparison. For

309 some of these taxonomic groups, multiple gene sets used in MLSA are available, and the user

310 must therefore select the appropriate set for analysis. FASTA formatted gene sequences are

311 input, and after selecting the appropriate options for alignment and tree parameters, a 
312 phylogenetic tree that includes the isolate of interest is generated and displayed. The tree

313 parameters include choice of distance matrix, tree generating algorithm (Neighbor-Joining or

314 UPGMA), and number of bootstrap replicates. A sub-clade of the tree containing only the isolate

315 of interest and its nearest sister taxa is displayed to the right of the full tree. The tree can be

316 saved as a Newick file or as a PDF. An example sequence from Agrobacterium can be loaded by

317 clicking the "Demo" button located in the Agro-type tab.

318

319 Phytopath-Type

320 The "Phytopath-Type" tab provides online tools for the analysis of other non-gall-causing

321 pathogens important in agriculture (Mansfield et al. 2012). This tool is similar in function to the

322 "Gall Isolate Typing" tools, except it is not limited to a single taxon of pathogen. A database of

323 16S rDNA sequences from genera of important bacterial phytopathogens (Pseudomonas

324 syringae group, Ralstonia, Agrobacterium, Rhodococcus, Xanthomonas, Pantoea, Xylella,

325 Dickeya, Pectobacterium, and Clavibacter) is available for associating a bacterial pathogen to its

326 genus. Additionally, for Clavibacter, Dickeya, Pectobacterium, Ralstonia, Xanthomonas, and

327 Xylella, the user can use MLSA to genotype isolates of interest. As is the case with Gall Isolate

328 Typing, a phylogenetic tree will be generated and displayed, associating the isolate of interest to

329 the most closely related genotype in the curated databases.

330

331 Vir-Search

332 The "Vir-Search" tab provides an online tool for using user-input read sequences of a

333 genome to search for the presence of homologs of known virulence genes. Users select a

334 taxonomic group (Agrobacterium, P. savastanoi, P. agglomerans, or Rhodococcus) to designate 
335 the set of virulence genes to search against. Users also determine a minimum percent gene

336 coverage and maximum allowed percent identity divergence, and upload single or paired read

337 files in FASTQ format. The user-supplied read sequences are then aligned to the chosen

338 virulence gene dataset on the Gall-ID server. Once the search is complete, a link to the final

339 results is sent to a user-provided email address. Results display the percent coverage of the

340 virulence genes and the percent similarity of the covered sequences. If the query identifies

341 multiple alleles of virulence genes from different sequenced strains, the Vir-Search tool will

342 report the strain name associated with the best-mapped allele. User-submitted data and results are

343 confidential and submitted sequencing reads are deleted from the Gall-ID server upon

344 completion of the analysis.

345

346

\section{Databases of Gall-ID}

A key component of the tools associated with the aforementioned tabs is the manually

curated databases of gene sequences. The literature was reviewed to identify validated taxon-

specific sets of genes for MLSA of taxa with gall-causing bacteria as well as other pathogens that

affect agriculture (Table 1) (Sarkar \& Guttman 2004; Hwang et al. 2005; Castillo \& Greenberg

351

2007; Alexandre et al. 2008; Young et al. 2008; Delétoile et al. 2009; Kim et al. 2009; Adékambi

352

et al. 2011; Jacques et al. 2012; Parker et al. 2012; Marrero et al. 2013; Pérez-Yépez et al. 2014;

353 Tancos et al. 2015). The sequences for the corresponding genes were subsequently extracted

354 from the whole genome sequences of reference strains. Auto MLSA was employed to use the

355 gene sequences as queries in BLAST searches. Auto MLSA is based on a previously developed

356 set of Perl scripts to automate retrieving, filtering, aligning, concatenating, determining of best

357 substitution models, appending of key identifiers to sequences, and generating files for tree 
358 construction (Creason et al. 2014a). Gene sets in which there were less than $50 \%$ query sequence

359 coverage for all of the genes were excluded to ensure that the databases contained only

360 taxonomically informative sequences. Each gene set database was manually checked for

361 duplicate strains, large gaps in gene sequences, poor sequence alignment, and mis-annotated

362 taxonomic information. Each of the MLSA databases used in the Gall-ID tools is also available

363 for download on the "Database Downloads" tab of the Gall ID website. The 16S rDNA databases

364 were populated in a similar manner, with one small exception. For the Phytopath-Type tool, the

365 sequence of the $16 \mathrm{~S}$ rRNA-encoding gene from C58 of Agrobacterium was used as a query to

366 retrieve corresponding sequences from 345 isolates distributed across the different genera of

367 plant pathogenic bacteria.

368 To populate the database for virulence genes, the literature was reviewed to identify

369 genes with demonstrably necessary functions for the pathogenicity of Agrobacterium spp., $R$.

370 fascians, P. savastanoi, and P. agglomerans (Thompson et al. 1988; Ward et al. 1988; Lichter et

371 al. 1995; Nizan et al. 1997; Manulis et al. 1998; Zhu et al. 2000; Maes et al. 2001; Vereecke et

372 al. 2002; Nizan-Koren et al. 2003; Sisto et al. 2004; Nissan et al. 2006; Barash \& Manulis-

373 Sasson 2007; Matas et al. 2012). The gene sequences were downloaded from corresponding type

374 strains in the NCBI nucleotide (nr) database or from nucleotide sequences in the NCBI nr

375 database. The downloaded virulence gene sequences were then used as input for the Auto MLSA

376 tool to retrieve sequenced alleles from other isolates of the same taxa. The downloaded alleles

377 were manually inspected to ensure only pathogenic strains were represented. The database was

378 formatted for SRST2.

379

380 Whole Genome Analysis 
The analyses of whole genome sequence datasets can be computationally intensive,

382 which is prohibitive for online tools. Therefore, the "Whole Genome Analysis" tab provides

383 downloadable software pipeline tools for users to employ their institutional infrastructure or a

384 cloud computing service to analyze whole genome sequencing reads (Illumina HiSeq or MiSeq).

385 There are two options in this tab, the first, "WGS Pipeline: Core Genome Analysis," provides a

386 download link and instructions for using the WGS Pipeline tool to generate a phylogeny based

387 on the core genome sequence or core set of single nucleotide polymorphisms (SNPs). The

388 second option, “Auto ANI: Average Nucleotide Identity Analysis," provides a download link for

389 the Auto ANI tool and detailed instructions for its use in calculating all possible pairwise ANI

390 within a set of genome sequences.

391 The WGS Pipeline is a set of scripts that automates the use of sequences from Illumina-

392 based paired reads derived from whole genome sequencing projects to determine core genome

393 sequences or core SNPs and generate phylogenetic trees (Figure 2). This pipeline uses SMALT

394 and SSAHA2 pile-up pipeline to align sequencing reads to an indexed reference genome

395 sequence and generate a pileup file, respectively (Ning et al. 2001; Ponstingl 2013). The WGS

396 Pipeline then combines the pileup files along with other pre-computed pileup files to derive a

397 core genome alignment defined based on regions that are shared between at least $90 \%$ of the

398 compared genome sequences. Users have the option of using Gubbins to remove regions that are

399 flagged as potentially derived from recombination (Croucher et al. 2014). Invoking Gubbins will

400 also remove all non-polymorphic sites from the alignments, thus yielding a SNP alignment that

401 is based only on polymorphic sites that are identified as vertically inherited and shared between

402 at least $90 \%$ of the compared genome sequences. Finally, the user can use either the core genome 
403 sequence or core SNP alignment and RAxML to generate a maximum likelihood (ML)

404 phylogeny (Stamatakis 2014).

405 Users must place their input files in the correspondingly named folders in order to run the

406 WGS pipeline. The pipeline down weights reads with a $\mathrm{Q}$ score of $<30$, requires a minimum

407 depth of 12 and relies on a minimum threshold of $75 \%$ for consensus base calling. Users

408 concerned with sequencing quality may, prior to running the WGS pipeline, run programs such

409 as FastQC, Trimmomatic, Sickle, and/or BBDuk to filter reads based on quality threshold

410 (Andrews 2010; Joshi \& Fass 2011; Bolger et al. 2014; Bushnell 2016). Paired read sequences

411 for each genome are read from the "reads" folder, while a SMALT index named as "reference"

412 and placed in the "index" folder will be used as a reference to align to. Identifiers are taken from

413 the prefix of the read pair file names and used to name the output pileup files and taxa in the

414 phylogeny. The read pair file names must have the suffixes ".1.fastq" and ".2.fastq" for files with

415 forward and reverse read sequences, respectively. The read sequences must be in FASTQ format

416 and because of requirements of the SMALT program, each paired read name must end in ".p1k"

417 and ".q1k" for forward and reverse reads, respectively. If the input read sequences are not in the

418 proper format, the user may run the included optional script "prepare_for_pileup.sh" to format

419 read names. If the user has pre-computed SMALT pileup files prepared using the same SMALT

420 index, the files may be placed in the "pileup" folder and will also be included in the analysis. The

421 user may be prompted to input the length of the inserts for each sequencing library. Users also

422 have the option of changing the number of ML searches or non-parametric bootstrap replicates

423 when building a phylogeny (default values are $20 \mathrm{ML}$ searches, autoMRE cutoff criterion for

424 bootstrap replicates). 
Agrobaterium and strain A44a of Rhodococcus, as well as pre-computed pileup files for 17

427 publicly available Rhodococcus genome sequences, are available for download on the Gall-ID

428 website. Detailed usage instructions and download links for the pipeline scripts are located in the

"WGS Pipeline: Core Genome Analysis" tool in the "Whole Genome Analysis" tab of Gall-ID.

Previously developed scripts for ANI analysis were rewritten and named Auto ANI. The

current version of these scripts alleviates dependencies on our institutional computational

infrastructure and increases the scalability of analyses (Creason et al. 2014a). Results are saved

in a manner that enables analyzing additional genomes without having to re-compute ANI values

for previously calculated comparisons. All BLAST searches are done in a modular manner and

can be modified to run on a computer cluster with a queuing system such as the Sun Grid

Engine. There are no inherent restrictions on the numbers of pairwise comparisons that can be

performed. The data are output as a tab delimited matrix of all pairwise comparisons and can

438 also easily be sorted and resorted based on any reference within the output. Additionally, genome

sequences with evidence for poor quality assemblies can be easily filtered out. A distance

440 dendrogram based on ANI divergence can also be generated; a python script is available for

441 download (Chan et al. 2012; Creason et al. 2014a).

442

\section{Validation of tools available in Gall-ID}

We validated the efficacy of the online tools available from the Gall Isolate Typing, and

445 Vir-Search tabs. DNA from 14 isolates were prepared, barcoded, and sequenced on an Illumina

446 MiSeq (Table 3). Of these isolates, the identities of 11 were previously verified as

447 Agrobacterium. The remaining three were associated with plant tissues showing symptoms of 
448 crown gall disease but were not tested or had results inconsistent with being a pathogenic

449 member of the Agrobacterium genus. The reads were trimmed for quality and first de novo

450 assembled within each library using the Velvet assembler (Zerbino \& Birney 2008). The $16 \mathrm{~S}$

451 gene sequences were identified and extracted from the assemblies and used as input for the

452 Agro-type tool. The $16 \mathrm{~S}$ gene sequences from each of the 11 isolates originally typed as

453 Agrobacterium clustered accordingly; isolate 13-2099-1-2 is shown as an example (Figure 3A).

454 The 16S sequence from isolates $\mathrm{AC} 27 / 96, \mathrm{AC} 44 / 96$, and 14-2641 were more distant from the

455 16S sequences of Agrobacterium (Table 3). The isolates AC27/96 and AC44/96 grouped more

456 closely with various Rhizobium species, while subsequent analysis using the Phytopath-Type tool

457 suggested isolate 14-2641 was more closely related to members of Erwinia, Dickeya, and

458 Pectobacterium (Table 3, Supplementary Figure 1). A search against the NCBI nr database

459 revealed similarities to members of Serratia.

460 The trimmed read sequences were used as input for the Vir-Search tool as an additional

461 step to confirm the identity of these isolates. Paired read sequences for each of the 14 isolates

462 were individually uploaded to the Gall-ID server. The Agrobacterium virulence gene database

463 was selected, with the minimum gene length coverage set to $80 \%$ and maximum allowed

464 sequence divergence set to $20 \%$. The time for each Vir-Search analysis ranged from 2-5 minutes.

465 Results suggested that the genome sequences for nearly all of the Agrobacterium isolates had

466 homologs of virulence genes demonstrably necessary for pathogenicity by Agrobacterium, while

467 the genome sequences for the isolates $\mathrm{AC} 27 / 96$, AC44/96, and 14-2641 did not (Figure 3B, data

468 for isolate 13-2099-1-2 shown). Contrary to the results from molecular diagnostics tests, the

469 reads from isolate 13-626 failed to align to any virulence genes except for two (nocM, nocP)

470 involved in nopaline transport. This isolate had the fewest number of useable sequencing reads 
471 and the highest number of contigs compared to the others, and results could have been a

472 consequence of a poor assembly of the Ti plasmid.

473 Indeed, the qualities of the 14 assemblies were highly variable, likely reflecting the multi-

474 partite structure of the agrobacterial genomes, presence of a linear replicon, and/or variation in

475 depth of sequencing. We therefore used SPAdes v. 3.6.2 to de novo assemble each of the genome

476 sequences, with the exception of isolate 14-2641 (Bankevich et al. 2012). The total sizes of the

477 assemblies were similar to those generated using Velvet and the qualities of the assemblies were

478 high. But assemblies generated using SPAdes had proliferations in errors with palindromic

479 sequence that appeared to be unique to isolates expected to have linear replicons. We informed

480 the developers of the SPAdes software who immediately resolved the issue in SPAdes 3.7.0.

481 Inspection of the summary statistics of the assemblies derived using this latest version of SPAdes

482 suggested that relative to Velvet-based assemblies, there were improvements to all assemblies,

483 witht the most dramatic to those with the lowest read coverage (Supplementary Table 1,

484 Supplementary Figure 2). To further verify the quality of assemblies generated using SPAdes

485 3.7.0, we used Mauve to align Velvet and SPAdes assembled genome sequences of isolate 13-

486626 to the finished genome sequence of the reference sequence of $A$. radiobacter K84 (Darling et

487 al. 2004; Slater et al. 2009). The SPAdes-based assembly was superior in being less fragmented

488 and we were able to elevate the quality of the assembly from "unusable" to "high quality"

489 (Supplementary Figures 2 and 3). Therefore, there is greater confidence in concluding that

490 isolate 13-626 lacks the vir genes and T-DNA sequence. It does however have an $\sim 200 \mathrm{~kb}$

491 plasmid sequence which encodes nocM and nocP; this contig also encodes sequences common to

492 replication origins of plasmids. We therefore suggest that because an isolate from the same pear 
493 gall sample originally tested positive for virD2, we mistakenly sequenced a non-pathogenic 494 isolate.

495 To validate the WGS Pipeline tool of Gall-ID, Illumina paired end read sequences

496 derived from previously generated genome sequences of 20 Rhodococcus isolates were used to

497 construct a phylogeny based on SNPs (Creason et al. 2014a). Using default parameters, the entire

498 process, from piling up reads to generating the final phylogenetic tree, took 16 hours (Table 2).

499 A total of 855,355 sites (out of a total of 5,947,114 sites in the A44a reference sequence) were

500 shared in at least 18 of the 20 Rhodococcus genome sequences. Of the shared sites, 177,961 sites

501 were polymorphic, of which 3,142 were removed because they were identified as potentially

502 acquired by recombination. The final core SNP alignment was therefore represented by 174,819

503 polymorphic sites and used to construct a maximum likelihood tree (Figure 4). Most of the nodes

504 were well supported, with all exceeding 68\% bootstrap support and most having $100 \%$ support.

505 The topology of the tree was consistent with that derived from a multi-gene phylogeny (Creason

506 et al. 2014a). As previously reported, the 20 isolates formed two well-supported and distinct

507 clades, and could explain the relatively low number of shared SNPs. The substructure that was

508 previously observed in clade I was also evident in the ML tree based on core SNPs. The one

509 noticeable difference between the trees was that the tips of the tree based on the core SNPs had

510 substantially more resolution, and in particular, revealed a greater genetic distance between

511 isolates A76 and 05-339-1, than previously appreciated based on the multi-gene phylogeny.

512 The amount of time to run Auto ANI was determined by comparing genome assemblies

513 of the same 20 Rhodococcus isolates. The entire process was completed in five hours.

\section{Conclusions}


517 characterize gall-causing pathogenic bacterial isolates using Sanger sequencing or Illumina

518 sequencing. Though Gall-ID was developed with a particular focus on these types of bacteria, it

519 can be used for some of the more common and important agricultural bacterial pathogens.

520 Additionally, the downloadable tools can be used for any taxa of bacteria, regardless of whether

521 or not they are pathogens.

522

523 ACKNOWLEDGEMENTS

524 We thank Melodie Putnam for providing the 14 bacterial isolates and for critical reading 525 of the manuscript. We thank Dr. Pankaj Jaiswal for organizing and inviting us to participate in 526 the STEM DNA Biology and Bioinformatics summer camps (Oregon State University). Camp 527 participants, Ana Bechtel, Mason Hall, Reagan Hunt, Pranav Kolluri, Benjamin Phelps, Joshua 528 Phelps, Aravind Sriram, Megan Thorpe, and eight others, prepared genomic DNA and libraries

529 for whole genome sequencing and analyzed the data. We thank Charlie DuBois of Illumina for 530 providing kits for library preparation as well as sequencing, and Mark Dasenko, Matthew

531 Peterson, and Chris Sullivan of the Center for Genome Research and Biocomputing for 532 sequencing, data processing, and computing services. Finally, we thank the Department of

533 Botany and Plant Pathology for supporting the computational infrastructure. Any opinion,

534 findings, and conclusions or recommendations expressed in this material are those of the 535 authors(s) and do not necessarily reflect the views of the U. S. Department of Agriculture or 536 National Science Foundation. 
539 Figure 1. Overview of Gall-ID diagnostic tools. DNA sequence information can be used to

540

541

542

543

544

545

546

547

548

549

550

551

552

553

554

555

556

557

558

559

560

561

562

563

564

565

566

567

568

569

570

571

572

573

574

575

576

577 reveal the identity of the causative agent (unknown isolate) of disease. Tools associated with "Gall Isolate Typing" and "Phytopath-type" use 16S rDNA or pathogen-specific MLSA gene sequences to infer the identity of the isolate by comparing the sequences to manually curated sequence databases. Tools associated with "Whole Genome Analysis" and "Vir-Search" use Illumina short sequencing reads to characterize pathogenic isolates. The former tab provides downloadable tools to infer genetic relatedness based on SNPs (WGS Pipeline) or average nucleotide identity (Auto ANI). The "Vir-Search" tab provides an on-line tool to quickly map short reads against a database of sequences of virulence genes.

Figure 2. Flowchart for the WGS Pipeline. Scripts and the programs that each script runs are boxed and presented along the left. The logic flow of the WGS Pipeline tool is presented along the right. Rectangles with rounded corners = inputs and outputs; boxes outlined in red = processes. The inputs, outputs, and processes are matched to the corresponding script and program.

Figure 3. Validation of the Agro-type and Vir-Search tools. A) An unrooted Neighbor Joining phylogenetic tree based on 16s rDNA sequences from Agrobacterium spp. The 16S rDNA sequence was identified and extracted from the genome assembly of Agrobacterium isolate 132099-1-2 and analyzed using the tool available in the Agro-type tab. The isolate is labeled in red, as "query_isolate"; inset shows the clade that circumscribes the isolate. B) Screenshot of output results from Vir-Search. Paired 2x300 bp MiSeq short reads from Agrobacterium isolate 132099-1-2 were analyzed using the Vir-Search tool in Gall-ID. Reference virulence gene sequences that were aligned are indicated with a green plus ("+") icon and the lengths and depths of the read coverage are reported (must exceed user-specified cutoffs, which were designated as $90 \%$ minimum coverage and $20 \%$ maximum sequence divergence). Virulence genes that failed to exceed user-specific cutoffs for read alignment parameters are indicated with a red "X". Virulence genes are grouped into categories based on their function in virulence.

\section{Figure 4. Maximum likelihood tree based on vertically inherited polymorphic sites core to} 20 Rhodococcus isolates. WGS Pipeline was used to automate the processing of paired end short reads from 20 previously sequenced Rhodococcus isolates, and generate a maximum likelihood unrooted tree. Sequencing reads were aligned, using $R$. fascians strain A44a as a reference. SNPs potentially acquired via recombination were removed. The tree is midpoint-rooted. Scale bar $=0.05$ average substitutions per site; non-parametric bootstrap support as percentages are indicated for each node. Major clades and sub-clades are labeled in a manner consistent with previous labels. 
578

579

580

581

582

583

584

585

586

587

588

589

590

591

592

593

594

595

596

597

598

599

600

601

602

603

604

605

606

607

608

609

610

611

612

613

614

615

616

617

618

619

620

621

622

\section{REFERENCES}

Adékambi T, Butler RW, Hanrahan F, Delcher AL, Drancourt M, and Shinnick TM. 2011. Core gene set as the basis of multilocus sequence analysis of the subclass Actinobacteridae. PLoS One 6:e14792. 10.1371/journal.pone.0014792

Alexandre A, Laranjo M, Young JP, and Oliveira S. 2008. dnaJ is a useful phylogenetic marker for Alphaproteobacteria. International Journal of Systematic and Evolutionary Microbiology 58:2839-2849. 10.1099/ijs.0.2008/001636-0

Allardet-Servent A, Michaux-Charachon S, Jumas-Bilak E, Karayan L, and Ramuz M. 1993. Presence of one linear and one circular chromosome in the Agrobacterium tumefaciens C58 genome. Journal of Bacteriology 175:7869-7874.

Alvarez AM. 2004. Integrated approaches for detection of plant pathogenic bacteria and diagnosis of bacterial diseases. Annual Review of Phytopathology 42:339-366. doi:10.1146/annurev.phyto.42.040803.140329

Andrews S. 2010. FastQC A quality control tool for high throughput sequence data. Available at http://www.bioinformatics.babraham.ac.uk/projects/fastqc/.

Aragon IM, Perez-Martinez I, Moreno-Perez A, Cerezo M, and Ramos C. 2014. New insights into the role of indole-3-acetic acid in the virulence of Pseudomonas savastanoi pv. savastanoi. FEMS Microbiol Letters 356:184-192. 10.1111/1574-6968.12413

Bankevich A, Nurk S, Antipov D, Gurevich A, Dvorkin M, Kulikov A, Lesin V, Nikolenko S, Pham S, Prjibelski A, Pyshkin A, Sirotkin A, Vyahhi N, Tesler G, Alekseyev M, and Pevzner P. 2012. SPAdes: a new genome assembly algorithm and its applications to single-cell sequencing. J Comput Biol 19:455-477. 10.1089/cmb.2012.0021

Barash I, and Manulis S. 2005. Hrp-dependent biotrophic mechanism of virulence: How has it evolved in tumorigenic bacteria? Phytoparasitica 33:317-324. 10.1007/BF02981296

Barash I, and Manulis-Sasson S. 2007. Virulence mechanisms and host specificity of gallforming Pantoea agglomerans. Trends in Microbiology 15:538-545. 10.1016/j.tim.2007.10.009

Barash I, Panijel M, Gurel F, Chalupowicz L, and Manulis S. 2005. Transformation of Pantoea agglomerans into a tumorigenic pathogen. In: Sorvari S, and Toldi O, editors. Proceedings of the 1st International Conference on Plant-Microbe Interactions: Endophytes and Biocontriol Agents. Lapland, Finland: Saariselka. p 10-19.

Bardaji L, Perez-Martinez I, Rodriguez-Moreno L, Rodriguez-Palenzuela P, Sundin GW, Ramos C, and Murillo J. 2011. Sequence and role in virulence of the three plasmid complement of the model tumor-inducing bacterium Pseudomonas savastanoi pv. savastanoi NCPPB 3335. PLoS One 6:e25705. 10.1371/journal.pone.0025705

Binns AN, and Costantino P. 1998. The Agrobacterium oncogenes. In: Spaink HP, Kondorosi A, and Hooykaas PJJ, eds. The Rhizobiaceae. Netherlands: Springer, 251-166.

Bolger A, Lohse M, and Usadel B. 2014. Trimmomatic: a flexible trimmer for Illumina sequence data. Bioinformatics 30:2114-2120. 10.1093/bioinformatics/btu170

Bomhoff G, Klapwijk PM, Kester HC, Schilperoort RA, Hernalsteens JP, and Schell J. 1976. Octopine and nopaline synthesis and breakdown genetically controlled by a plasmid of Agrobacterium tumefaciens. Molecular \& General Genetics 145:177-181.

Bouzar H, and Jones JB. 2001. Agrobacterium larrymoorei sp. nov., a pathogen isolated from aerial tumours of Ficus benjamina. International Journal of Systematic and Evolutionary Microbiology 51:1023-1026. 10.1099/00207713-51-3-1023 
623

624

625

626

627

628

629

630

631

632

633

634

635

636

637

638

639

640

641

642

643

644

645

646

647

648

649

650

651

652

653

654

655

656

657

658

659

660

661

662

663

664

665

666

667

668

Broothaerts W, Mitchell HJ, Weir B, Kaines S, Smith LMA, Yang W, Mayer JE, Roa-Rodríguez C, and Jefferson RA. 2005. Gene transfer to plants by diverse species of bacteria. Nature 433:629-633. 10.1038/nature03309

Burr T, Katz B, Abawi G, and Crosier D. 1991. Comparison of tumorigenic strains of Erwinia herbicola isolated from table beet with E. h. gypsophilae. Plant Disease 75:855-858.

Bushnell B. 2016. BBMap. Available at http://sourceforge.net/projects/bbmap/.

Castillo JA, and Greenberg JT. 2007. Evolutionary dynamics of Ralstonia solanacearum. Applied and Environmental Microbiology 73:1225-1238. 10.1128/AEM.01253-06

Castresana J. 2000. Selection of conserved blocks from multiple alignments for their use in phylogenetic analysis. Molecular Biology and Evolution 17:540-552.

Chan JZ-M, Halachev MR, Loman NJ, Constantinidou C, and Pallen MJ. 2012. Defining bacterial species in the genomic era: insights from the genus Acinetobacter. BMC Microbiology 12:302. 10.1186/1471-2180-12-302

Chang J-M, Di Tommaso P, and Notredame C. 2014. TCS: A new multiple sequence alignment reliability measure to estimate alignment accuracy and improve phylogenetic tree reconstruction. Molecular Biology and Evolution 31:1625-1637. 10.1093/molbev/msu117

Chilton MD, Drummond MH, Merio DJ, Sciaky D, Montoya AL, Gordon MP, and Nester EW. 1977. Stable incorporation of plasmid DNA into higher plant cells: the molecular basis of crown gall tumorigenesis. Cell 11:263-271.

Clark E, Manulis S, Ophir Y, Barash I, and Y G. 1993. Cloning and characterization of iaaM and iaaH from Erwinia herbicola pathovar gypsophilae. Phytopathology 83:234-240. 10.1094/Phyto-83-234

Cooksey DA. 1986. Galls of Gypsophila paniculata caused by Erwinia herbicola. Plant Disease 70:464. 10.1094/PD-70-464

Creason AL, Davis EW, Putnam ML, Vandeputte OM, and Chang JH. 2014a. Use of whole genome sequences to develop a molecular phylogenetic framework for Rhodococcus fascians and the Rhodococcus genus. Frontiers in Plant Science 5:406. 10.3389/fpls.2014.00406

Creason AL, Vandeputte OM, Savory EA, Davis EW, Putnam ML, Hu E, Swader-Hines D, Mol A, Baucher M, Prinsen E, Zdanowska M, Givan SA, Jaziri ME, Loper JE, Mahmud T, and Chang JH. 2014b. Analysis of genome sequences from plant pathogenic Rhodococcus reveals genetic novelties in virulence loci. PLoS One 9:e101996. 10.1371/journal.pone.0101996

Crespi M, Messens E, Caplan AB, van Montagu M, and Desomer J. 1992. Fasciation induction by the phytopathogen Rhodococcus fascians depends upon a linear plasmid encoding a cytokinin synthase gene. The EMBO Journal 11:795-804.

Croucher NJ, Page AJ, Connor TR, Delaney AJ, Keane JA, Bentley SD, Parkhill J, and Harris SR. 2014. Rapid phylogenetic analysis of large samples of recombinant bacterial whole genome sequences using Gubbins. Nucleic Acids Research:gku1196-. 10.1093/nar/gku1196

Darling A, Mau B, Blattner F, and Perna N. 2004. Mauve: multiple alignment of conserved genomic sequence with rearrangements. Genome Res 14:1394-1403. 10.1101/gr.2289704

Delétoile A, Decré D, Courant S, Passet V, Audo J, Grimont P, Arlet G, and Brisse S. 2009. Phylogeny and identification of Pantoea species and typing of Pantoea agglomerans strains by multilocus gene sequencing. Journal of Clinical Microbiology 47:300-310. 10.1128/JCM.01916-08 
669 DeYoung RM, Copeman RJ, and Hunt RS. 1998. Two strains in the genus Erwinia cause galls

670

671

672

673

674

675

676

677

678

679

680

681

682

683

684

685

686

687

688

689

690

691

692

693

694

695

696

697

698

699

700

701

702

703

704

705

706

707

708

709

710

711

712

713

714 on Douglas-fir in southwestern British Columbia. Canadian Journal of Plant Pathology 20:194-200. 10.1080/07060669809500427

Farrand SK, Van Berkum PB, and Oger P. 2003. Agrobacterium is a definable genus of the family Rhizobiaceae. International Journal of Systematic and Evolutionary Microbiology 53:1681-1687. 10.1099/ijs.0.02445-0

Gardan L, Bollet C, Abu Ghorrah M, Grimont F, and Grimont PAD. 1992. DNA relatedness among the pathovar strains of Pseudomonas syringae subsp. savastanoi Janse (1982) and proposal of Pseudomonas savastanoi sp. nov. International Journal of Systematic Bacteriology 42:606-612. 10.1099/00207713-42-4-606

Gloyer WO. 1934. Crown gall and hairy root of apples in nursery and orchard. Geneva, NY: New York Agricultural Experiment Station Bulletin 638.

Goodfellow M. 1984. Reclassification of Corynebacterium fascians (Tilford) Dowson in the genus Rhodococcus, as Rhodococcus fascians comb. nov. Systematic and Applied Microbiology 5:225-229. 10.1016/S0723-2020(84)80023-5

Goris J, Konstantinidis KT, Klappenbach JA, Coenye T, Vandamme P, and Tiedje JM. 2007. DNA-DNA hybridization values and their relationship to whole-genome sequence similarities. International Journal of Systematic and Evolutionary Microbiology 57:8191. 10.1099/ijs.0.64483-0

Heibl C. 2013. PHYLOCH: interfaces and graphic tools for phylogenetic data in R. Available at http://www.christophheibl.de/Rpackages.html.

Hildebrand EM. 1940. Cane gall of Brambles caused by Phytomonas rubi n.sp. Journal of Agricultural Research 61:685--696 pp.

Hwang MSH, Morgan RL, Sarkar SF, Wang PW, and Guttman DS. 2005. Phylogenetic characterization of virulence and resistance phenotypes of Pseudomonas syringae. Applied and Environmental Microbiology 71:5182-5191. 10.1128/AEM.71.9.51825191.2005

Iacobellis NS, Sisto A, Surico G, Evidente A, and DiMaio E. 1994. Pathogenicity of Pseudomonas syringae subsp. savastanoi mutants defective in phytohormone production. Journal of Phytopathology 140:238-248. 10.1111/j.1439-0434.1994.tb04813.x

Inouye M, Conway TC, Zobel J, and Holt KE. 2012. Short read sequence typing (SRST): multilocus sequence types from short reads. BMC Genomics 13:338. 10.1186/1471-2164-13338

Inouye M, Dashnow H, Raven L-A, Schultz MB, Pope BJ, Tomita T, Zobel J, and Holt KE. 2014. SRST2: Rapid genomic surveillance for public health and hospital microbiology labs. Genome Medicine 6:90. 10.1186/s13073-014-0090-6

Jacques M-A, Durand K, Orgeur G, Balidas S, Fricot C, Bonneau S, Quillévéré A, Audusseau C, Olivier V, Grimault V, and Mathis R. 2012. Phylogenetic analysis and polyphasic characterization of Clavibacter michiganensis strains isolated from tomato seeds reveal that nonpathogenic strains are distinct from $C$. michiganensis subsp. michiganensis. Applied and Environmental Microbiology 78:8388-8402. 10.1128/AEM.02158-12

Janda JM, and Abbott SL. 2007. 16S rRNA gene sequencing for bacterial identification in the diagnostic laboratory: pluses, perils, and pitfalls. Journal of Clinical Microbiology 45:2761-2764. 10.1128/JCM.01228-07

Joshi N, and Fass J. 2011. Sickle: A sliding-window, adaptive, quality-based trimming tool for FastQ files. Available at https://github.com/najoshi/sickle. 
715 Kado CI. 2014. Historical account on gaining insights on the mechanism of crown gall 716 tumorigenesis induced by Agrobacterium tumefaciens. Frontiers in Microbiology 5:340. $717 \quad 10.3389 /$ fmicb.2014.00340

718 Kamvar ZN, Tabima JF, and Grünwald NJ. 2014. Poppr: an R package for genetic analysis of 719 populations with clonal, partially clonal, and/or sexual reproduction. PeerJ 2:e281.

722

723

724

725

726

727

728

729

730

731

732

733

734

735

736

737

738

739

740

741

742

743

744

745

746

747

748

749

750

751

752

753

754

755

756

757

758

759

760

Katoh K, and Standley DM. 2013. MAFFT multiple sequence alignment software version 7: Improvements in performance and usability. Molecular Biology and Evolution 30:772780. 10.1093/molbev/mst010

Katoh K, and Toh H. 2008. Recent developments in the MAFFT multiple sequence alignment program. Briefings in Bioinformatics 9:286-298. 10.1093/bib/bbn013

Kim H-S, Ma B, Perna NT, and Charkowski AO. 2009. Phylogeny and virulence of naturally occurring type III secretion system-deficient Pectobacterium strains. Applied and Environmental Microbiology 75:4539-4549. 10.1128/AEM.01336-08

Kim M, Oh H-S, Park S-C, and Chun J. 2014. Towards a taxonomic coherence between average nucleotide identity and 16S rRNA gene sequence similarity for species demarcation of prokaryotes. International Journal of Systematic and Evolutionary Microbiology 64:346351. 10.1099/ijs.0.059774-0

Langmead B, and Salzberg SL. 2012. Fast gapped-read alignment with Bowtie 2. Nature Methods 9:357-359. 10.1038/nmeth.1923

Lassalle F, Campillo T, Vial L, Baude J, Costechareyre D, Chapulliot D, Shams M, Abrouk D, Lavire C, Oger-Desfeux C, Hommais F, Guéguen L, Daubin V, Muller D, and Nesme X. 2011. Genomic species are ecological species as revealed by comparative genomics in Agrobacterium tumefaciens. Genome Biology and Evolution 3:762-781. 10.1093/gbe/evr070

Li H, Handsaker B, Wysoker A, Fennell T, Ruan J, Homer N, Marth G, Abecasis G, Durbin R, and Genome Project Data Processing S. 2009. The Sequence Alignment/Map format and SAMtools. Bioinformatics 25:2078-2079.

Lichter A, Barash I, Valinsky L, and Manulis S. 1995. The genes involved in cytokinin biosynthesis in Erwinia herbicola pv. gypsophilae: characterization and role in gall formation. Journal of Bacteriology 177:4457-4465.

Maes T, Vereecke D, Ritsema T, Cornelis K, Thu HN, Van Montagu M, Holsters M, and Goethals K. 2001. The att locus of Rhodococcus fascians strain D188 is essential for full virulence on tobacco through the production of an autoregulatory compound. Molecular microbiology 42:13-28.

Mansfield J, Genin S, Magori S, Citovsky V, Sriariyanum M, Ronald P, Dow M, Verdier V, Beer SV, Machado MA, Toth I, Salmond G, and Foster GD. 2012. Top 10 plant pathogenic bacteria in molecular plant pathology. Molecular Plant Pathology 13:614629. 10.1111/j.1364-3703.2012.00804.x

Manulis S, and Barash I. 2003. The molecular basis for transformation of an epiphyte into a gallforming pathogen as exemplified by Erwinia herbicola pv. gypsophilae. Plant-Microbe Interactions 6:19-52.

Manulis S, Haviv-Chesner A, Brandl MT, Lindow SE, and Barash I. 1998. Differential involvement of indole-3-acetic acid biosynthetic pathways in pathogenicity and epiphytic fitness of Erwinia herbicola pv. gypsophilae. Molecular Plant-Microbe Interactions 11:634-642. 10.1094/MPMI.1998.11.7.634 
761

762

763

764

765

766

767

768

769

770

771

772

773

774

775

776

777

778

779

780

781

782

783

784

785

786

787

788

789

790

791

792

793

794

795

796

797

798

799

800

801

802

803

804

805

806

Marrero G, Schneider KL, Jenkins DM, and Alvarez AM. 2013. Phylogeny and classification of Dickeya based on multilocus sequence analysis. International Journal of Systematic and Evolutionary Microbiology 63:3524-3539. 10.1099/ijs.0.046490-0

Matas IM, Lambertsen L, Rodríguez-Moreno L, and Ramos C. 2012. Identification of novel virulence genes and metabolic pathways required for full fitness of Pseudomonas savastanoi pv. savastanoi in olive (Olea europaea) knots. New Phytologist 196:11821196. 10.1111/j.1469-8137.2012.04357.x

Montoya AL, Chilton MD, Gordon MP, Sciaky D, and Nester EW. 1977. Octopine and nopaline metabolism in Agrobacterium tumefaciens and crown gall tumor cells: role of plasmid genes. Journal of Bacteriology 129:101-107.

Mor H, Manulis S, Zuck M, Nizan R, Coplin DL, and Barash I. 2001. Genetic organization of the hrp gene cluster and $d s p A E / B F$ operon in Erwinia herbicola pv. gypsophilae. Molecular Plant-Microbe Interactions 14:431-436. 10.1094/MPMI.2001.14.3.431

Morris RO. 1986. Genes specifying auxin and cytokinin biosynthesis in phytopathogens. Annual Review of Plant Physiology 37:509-538. 10.1146/annurev.pp.37.060186.002453

Ning Z, Cox AJ, and Mullikin JC. 2001. SSAHA: a fast search method for large DNA databases. Genome Research 11:1725-1729. 10.1101/gr.194201

Nissan G, Manulis-Sasson S, Weinthal D, Mor H, Sessa G, and Barash I. 2006. The type III effectors HsvG and HsvB of gall-forming Pantoea agglomerans determine host specificity and function as transcriptional activators. Molecular microbiology 61:11181131. 10.1111/j.1365-2958.2006.05301.x

Nizan R, Barash I, Valinsky L, Lichter A, and Manulis S. 1997. The presence of hrp genes on the pathogenicity-associated plasmid of the tumorigenic bacterium Erwinia herbicola pv. gypsophilae. Molecular Plant-Microbe Interactions 10:677-682. 10.1094/MPMI.1997.10.5.677

Nizan-Koren R, Manulis S, Mor H, Iraki NM, and Barash I. 2003. The regulatory cascade that activates the Hrp regulon in Erwinia herbicola pv. gypsophilae. Molecular PlantMicrobe Interactions 16:249-260. 10.1094/MPMI.2003.16.3.249

Opgenorth DC, Hendson M, and Clark E. 1994. First report of bacterial gall of Wisteria sinensis caused by Erwinia herbicola pv. milletiae in California. Plant Disease 78:1217C. 10.1094/PD-78-1217C

Ophel K, and Kerr A. 1990. Agrobacterium vitis sp. nov. for Strains of Agrobacterium biovar 3 from Grapevines. International Journal of Systematic Bacteriology 40:236-241. 10.1099/00207713-40-3-236

Paradis E, Claude J, and Strimmer K. 2004. APE: Analyses of Phylogenetics and Evolution in R language. Bioinformatics 20:289-290. 10.1093/bioinformatics/btg412

Parker JK, Havird JC, and De La Fuente L. 2012. Differentiation of Xylella fastidiosa strains via multilocus sequence analysis of environmentally mediated genes (MLSA-E). Applied and Environmental Microbiology 78:1385-1396. 10.1128/AEM.06679-11

Pearson T, Okinaka RT, Foster JT, and Keim P. 2009. Phylogenetic understanding of clonal populations in an era of whole genome sequencing. Infection, genetics and evolution : journal of molecular epidemiology and evolutionary genetics in infectious diseases 9:1010-1019. 10.1016/j.meegid.2009.05.014

Pérez-Yépez J, Armas-Capote N, Velázquez E, Pérez-Galdona R, Rivas R, and León-Barrios M. 2014. Evaluation of seven housekeeping genes for multilocus sequence analysis of the genus Mesorhizobium: Resolving the taxonomic affiliation of the Cicer canariense 
807

808

809

810

811

812

813

814

815

816

817

818

819

820

821

822

823

824

825

826

827

828

829

830

831

832

833

834

835

836

837

838

839

840

841

842

843

844

845

846

847

848

849

850

851 rhizobia. Systematic and Applied Microbiology

$37: 553-559$

Ponstingl H. 2013. SMALT. Available at https://www.sanger.ac.uk/resources/software/smalt/.

Putnam ML, and Miller ML. 2007. Rhodococcus fascians in herbaceous perennials. Plant Disease 91:1064-1076. 10.1094/PDIS-91-9-1064

Sachs T. 1975. Plant tumors resulting from unregulated hormone synthesis. Journal of Theoretical Biology 55:445-453.

Sarkar SF, and Guttman DS. 2004. Evolution of the core genome of Pseudomonas syringae, a highly clonal, endemic plant pathogen. Applied and Environmental Microbiology 70:1999-2012.

Schroth MN. 1988. Reduction in yield and vigor of grapevine caused by crown gall disease. Plant Disease 72:241. 10.1094/PD-72-0241

Sisto A, Cipriani MG, and Morea M. 2004. Knot Formation caused by Pseudomonas syringae subsp. savastanoi on olive plants is hrp-dependent. Phytopathology 94:484-489. 10.1094/PHYTO.2004.94.5.484

Slater S, Goldman B, Goodner B, Setubal J, Farrand S, Nester E, Burr T, Banta L, Dickerman A, Paulsen I, Otten L, Suen G, Welch R, Almeida N, Arnold F, Burton O, Du Z, Ewing A, Godsy E, Heisel S, Houmiel K, Jhaveri J, Lu J, Miller N, Norton S, Chen Q, Phoolcharoen W, Ohlin V, Ondrusek D, Pride N, Stricklin S, Sun J, Wheeler C, Wilson L, Zhu H, and Wood D. 2009. Genome sequences of three agrobacterium biovars help elucidate the evolution of multichromosome genomes in bacteria. J Bacteriol 191:25012511. 10.1128/JB.01779-08

Stackebrandt E, and Goebel BM. 1994. Taxonomic Note: A place for DNA-DNA reassociation and $16 \mathrm{~S}$ rRNA sequence analysis in the present species definition in bacteriology. International Journal of Systematic Bacteriology 44:846-849. 10.1099/00207713-44-4846

Stajich JE. 2002. The Bioperl Toolkit: Perl modules for the life sciences. Genome Research 12:1611-1618. 10.1101/gr.361602

Stamatakis A. 2014. RAxML version 8: a tool for phylogenetic analysis and post-analysis of large phylogenies. Bioinformatics 30:1312-1313. 10.1093/bioinformatics/btu033

Stes E, Francis I, Pertry I, Dolzblasz A, Depuydt S, and Vereecke D. 2013. The leafy gall syndrome induced by Rhodococcus fascians. FEMS Microbiol Lett 342:187-195. 10.1111/1574-6968.12119

Tancos MA, Lange HW, and Smart CD. 2015. Characterizing the genetic diversity of the Clavibacter michiganensis subsp. michiganensis population in New York. Phytopathology 105:169-179. 10.1094/PHYTO-06-14-0178-R

Temmerman W, Vereecke D, Dreesen R, Van Montagu M, Holsters M, and Goethals K. 2000. Leafy gall formation is controlled by fas $R$, an AraC-type regulatory gene in Rhodococcus fascians. Journal of Bacteriology 182:5832-5840.

Thompson DV, Melchers LS, Idler KB, Schilperoort RA, and Hooykaas PJ. 1988. Analysis of the complete nucleotide sequence of the Agrobacterium tumefaciens virB operon. Nucleic Acids Research 16:4621-4636.

Van Larebeke N, Engler G, Holsters M, Van den Elsacker S, Zaenen I, Schilperoort RA, and Schell J. 1974. Large plasmid in Agrobacterium tumefaciens essential for crown gallinducing ability. Nature 252:169-170. 
852 Vasanthakumar A, and McManus PS. 2004. Indole-3-acetic acid-producing bacteria are 853 associated with cranberry stem gall. Phytopathology 94:1164-1171.

854

855

856

857

858

859

860

861

862

863

864

865

866

867

868

869

870

871

872

873

874

875

876

877

878

879

880

881

882

883

884

885

886

887

888

889

890

891

892 10.1094/PHYTO.2004.94.11.1164

Velázquez E, Palomo JL, Rivas R, Guerra H, Peix A, Trujillo ME, García-Benavides P, Mateos PF, Wabiko H, and Martínez-Molina E. 2010. Analysis of core genes supports the reclassification of strains Agrobacterium radiobacter $\mathrm{K} 84$ and Agrobacterium tumefaciens AKE10 into the species Rhizobium rhizogenes. Systematic and Applied Microbiology 33:247-251. 10.1016/j.syapm.2010.04.004

Vereecke D, Cornelis K, Temmerman W, Jaziri M, Van Montagu M, Holsters M, and Goethals K. 2002. Chromosomal locus that affects pathogenicity of Rhodococcus fascians. Journal of Bacteriology 184:1112-1120.

Ward JE, Akiyoshi DE, Regier D, Datta A, Gordon MP, and Nester EW. 1988. Characterization of the virB operon from an Agrobacterium tumefaciens Ti plasmid. Journal of Biological Chemistry 263:5804-5814.

Weinthal DM, Barash I, Panijel M, Valinsky L, Gaba V, and Manulis-Sasson S. 2007. Distribution and replication of the pathogenicity plasmid pPATH in diverse populations of the gall-forming bacterium Pantoea agglomerans. Applied and Environmental Microbiology 73:7552-7561. 10.1128/AEM.01511-07

Wertz JE, Goldstone C, Gordon DM, and Riley MA. 2003. A molecular phylogeny of enteric bacteria and implications for a bacterial species concept. Journal of Evolutionary Biology 16:1236-1248.

Young JM. 2003. Classification and nomenclature of Agrobacterium and Rhizobium - a reply to Farrand et al. (2003). International Journal of Systematic and Evolutionary Microbiology 53:1689-1695. 10.1099/ijs.0.02762-0

Young JM, Kuykendall LD, Martínez-Romero E, Kerr A, and Sawada H. 2001. A revision of Rhizobium Frank 1889, with an emended description of the genus, and the inclusion of all species of Agrobacterium Conn 1942 and Allorhizobium undicola de Lajudie et al. 1998 as new combinations: Rhizobium radiobacter, R. rhizogenes, R. rubi, R. undicola and R. vitis. International Journal of Systematic and Evolutionary Microbiology 51:89-103. doi:10.1099/00207713-51-1-89

Young JM, Park D-C, Shearman HM, and Fargier E. 2008. A multilocus sequence analysis of the genus Xanthomonas. Systematic and Applied Microbiology 31:366-377. 10.1016/j.syapm.2008.06.004

Zeigler DR. 2003. Gene sequences useful for predicting relatedness of whole genomes in bacteria. International Journal of Systematic and Evolutionary Microbiology 53:18931900.

Zerbino DR, and Birney E. 2008. Velvet: Algorithms for de novo short read assembly using de Bruijn graphs. Genome Research 18:821-829. 10.1101/gr.074492.107

Zhu J, Oger PM, Schrammeijer B, Hooykaas PJ, Farrand SK, and Winans SC. 2000. The bases of crown gall tumorigenesis. Journal of Bacteriology 182:3885-3895. 


\section{Table 1 (on next page)}

Manually curated datasets developed for Gall-ID 
1 Table 1. Manually curated datasets developed for Gall-ID

\begin{tabular}{|c|c|c|c|}
\hline Database & Bacterial group & $\begin{array}{c}\text { \# of isolates used in } \\
\text { Gall-ID }\end{array}$ & References \\
\hline \multicolumn{4}{|c|}{ "Agro-type" tool (Agrobacterium) } \\
\hline $\begin{array}{l}\text { MLSA }(\text { dnaK, } g \ln A \text {, } \\
\operatorname{gyr} B, \operatorname{rec} A, \operatorname{rpoB}, \operatorname{thr} A, \\
\operatorname{tru} A)\end{array}$ & Rhizobiaceae & 199 & $\begin{array}{l}\text { Perez-Yepez et } \\
\text { al., }\end{array}$ \\
\hline $\begin{array}{l}\text { MLSA }(\operatorname{atpD}, \quad \text { gap } A, \\
g y r B, \operatorname{rec} A, \operatorname{rplB})\end{array}$ & Rhizobiaceae & 188 & $\begin{array}{l}\text { Alexandre et al., } \\
2008\end{array}$ \\
\hline dnaJ & Rhizobiaceae & 198 & $\begin{array}{l}\text { Alexandre et al., } \\
2008\end{array}$ \\
\hline $16 \mathrm{~S}$ rDNA & Rhizobiaceae & 245 & \\
\hline \multicolumn{4}{|c|}{ "Rhodo-type" tool (Rhodococcus) } \\
\hline $\begin{array}{l}\text { MLSA }(f t s Y, \inf B, r p o B \\
r s m A, \sec Y, t s a D, y c h F)\end{array}$ & Rhodococcus & 85 & $\begin{array}{l}\text { Adekambi et al., } \\
2011\end{array}$ \\
\hline $16 \mathrm{~S}$ rDNA & Rhodococcus & 66 & \\
\hline \multicolumn{4}{|c|}{ "Panto-type" tool (Pantoea agglomerans) } \\
\hline $\begin{array}{l}\text { MLSA } \quad(f u s A, \quad g y r B, \\
l e u S, p y r G, r p l B, r p o B)\end{array}$ & Pantoea, Erwinia & 356 & $\begin{array}{l}\text { Delétoile et al., } \\
2009\end{array}$ \\
\hline $16 \mathrm{~S}$ rDNA & Pantoea, Erwinia & 352 & \\
\hline \multicolumn{4}{|c|}{ "Pseudo-type" tool (Pseudomonas savastanoi) } \\
\hline $\begin{array}{l}\text { MLSA (gap } A, \quad \text { glt } A \text {, } \\
\text { gyrB, rpoD) }\end{array}$ & Pseudomonas syringae & 158 & $\begin{array}{l}\text { Hwang et al., } \\
2005\end{array}$ \\
\hline $\begin{array}{l}\text { MLSA }(a c n B, \quad \text { fruK, } \\
\text { gapA, glt } A, \quad \text { gyrB, pgi, } \\
\text { rpoD) }\end{array}$ & Pseudomonas syringae & 153 & $\begin{array}{l}\text { Sarkar et al., } \\
2004\end{array}$ \\
\hline 16S rDNA & Pseudomonas syringae & 161 & \\
\hline \multicolumn{4}{|l|}{ "Phytopath-type" tool } \\
\hline $16 \mathrm{~S}$ rDNA & $\begin{array}{l}\text { Rhodococcus, } \\
\text { Agrobacterium, } \\
\text { Pseudomonas syringae, } \\
\text { Ralstonia, Xanthomonas, } \\
\text { Pantoea, Erwinia, } \\
\text { Xylella, Dickeya, } \\
\text { Pectobacterium, }\end{array}$ & 345 & \\
\hline
\end{tabular}




\begin{tabular}{|l|l|l|l|}
\hline & $\begin{array}{l}\text { Clavibacter, } \\
\text { Rathayibacter }\end{array}$ & \\
\hline $\begin{array}{l}\text { MLSA (atpD, dnaK, } \\
\text { gyrB, ppK, recA, rpoB) }\end{array}$ & Clavibacter & 7 & $\begin{array}{l}\text { Jacques et al., } \\
2012\end{array}$ \\
\hline $\begin{array}{l}\text { MLSA (dnaA, gyrB, } \\
\text { kdpA, ligA, sdhA) }\end{array}$ & Clavibacter & 7 & $\begin{array}{l}\text { Tancos et al., } \\
2015\end{array}$ \\
\hline $\begin{array}{l}\text { MLSA (dnaA, dnaJ, } \\
\text { dnaX, gyrB, recN) }\end{array}$ & Dickeya & $\begin{array}{l}\text { Marrero et al., } \\
2013\end{array}$ \\
\hline $\begin{array}{l}\text { MLSA (acnA, gapA, } \\
\text { icdA, mdh, pgi) }\end{array}$ & Pectobacterium & 40 & Kim et al., 2009 \\
\hline $\begin{array}{l}\text { MLSA (adk, egl, fliC, } \\
\text { gapA, gdhA,gyrB, hrpB, } \\
\text { ppsA) }\end{array}$ & Ralstonia & 54 & $\begin{array}{l}\text { Castillo et al., } \\
2007\end{array}$ \\
\hline $\begin{array}{l}\text { MLSA (dnaK, fyuA, } \\
\text { gyrB, rpoD })\end{array}$ & Xanthomonas & 28 & $\begin{array}{l}\text { Young et al., } \\
2008\end{array}$ \\
\hline $\begin{array}{l}\text { MLSA }(a c v B, ~ c o p B, ~ \\
\text { cvaC, fimA, gaa, pglA, } \\
\text { pilA, rpfF, } x a d A)\end{array}$ & Xylella et al., \\
\hline
\end{tabular}


Table 2 (on next page)

Statistics for the WGS Pipeline 
1 Table 2. Statistics for the WGS Pipeline

\begin{tabular}{|c|c|c|}
\hline WGS Pipeline step & Statistic & Value \\
\hline \multirow{3}{*}{$\begin{array}{l}\text { generate_pileup.sh } \\
\text { (1 } 1 \text { cpu })\end{array}$} & Number of input paired read sets & 19 \\
\hline & $\begin{array}{l}\text { Average runtime per pileup } \\
\text { (hh:mm:ss) }\end{array}$ & $00: 42: 01$ \\
\hline & Total runtime (hh:mm:ss) & $13: 18: 14$ \\
\hline \multirow{3}{*}{$\begin{array}{c}\text { generate_core_alignment.sh } \\
(1 \mathrm{cpu})\end{array}$} & Total pileup alignment length & $5,947,114 \mathrm{bp}$ \\
\hline & $90 \%$-shared core alignment length & $855,355 \mathrm{bp}$ \\
\hline & Total runtime (hh:mm:ss) & $00: 15: 32$ \\
\hline \multirow{5}{*}{$\begin{array}{l}\text { remove_recombination.sh } \\
\text { (10 cpus) }\end{array}$} & Number of core polymorphic sites & $177,961 \mathrm{bp}$ \\
\hline & $\begin{array}{c}\text { core SNP alignment length } \\
\text { (w/o putative recombinant SNPs) }\end{array}$ & 174,819 bp \\
\hline & Computational time (hh:mm:ss) & $04: 25: 32$ \\
\hline & Actual runtime (hh:mm:ss) & $00: 29: 28$ \\
\hline & Figure output runtime (hh:mm:ss) & 00:13:03 \\
\hline \multirow{5}{*}{$\begin{array}{c}\text { generate phylogeny.sh } \\
\text { (raxmlHPC-PTHREADS- } \\
\text { AVX, } \\
10 \text { cpus })\end{array}$} & $\begin{array}{l}\text { Time to optimize RAxML } \\
\text { parameters (hh:mm:ss) }\end{array}$ & $00: 02: 32$ \\
\hline & $\begin{array}{l}\text { Time to compute } 20 \text { ML searches } \\
\text { (hh:mm:ss) }\end{array}$ & $00: 34: 53$ \\
\hline & $\begin{array}{l}\text { Number of bootstrap replicates } \\
\text { (RAxML autoMRE) }\end{array}$ & 50 \\
\hline & $\begin{array}{l}\text { Time to compute } 50 \text { bootstrap } \\
\text { searches (hh:mm:ss) }\end{array}$ & 01:02:09 \\
\hline & Total runtime (hh:mm:ss) & $01: 39: 34$ \\
\hline All & Total runtime (hh:mm:ss) & $15: 55: 51$ \\
\hline
\end{tabular}




\section{Table 3 (on next page)}

Strain identity of 14 isolates associated with crown gall 
1 Table 3. Strain identity of 14 isolates associated with crown gall

\begin{tabular}{|c|c|c|c|c|c|}
\hline $\begin{array}{l}\text { Isolate } \\
\text { name }\end{array}$ & Host & $\begin{array}{l}\text { Positive ID } \\
\text { based on }\end{array}$ & $\begin{array}{l}\text { \# high } \\
\text { quality } \\
\text { read } \\
\text { pairs }\end{array}$ & $\begin{array}{l}\text { Clade (based on } \\
16 \mathrm{~S} \text { rDNA) }\end{array}$ & $\begin{array}{l}\text { \# of } \\
\text { virulence } \\
\text { genes ID'ed }\end{array}$ \\
\hline $\begin{array}{l}13-2099- \\
1-2\end{array}$ & $\begin{array}{l}\text { Quaking } \\
\text { Aspen }\end{array}$ & virD2 PCR & $1,244,074$ & Agrobacterium & 63 \\
\hline $13-626$ & Pear & virD2 PCR & 220,903 & Agrobacterium & $\begin{array}{l}2 \text { (nocM, } \\
\text { nocP) }\end{array}$ \\
\hline $\mathrm{AC} 27 / 96$ & Pieris & Not pathogenic & 826,690 & Rhizobium & $1(t s s D)$ \\
\hline AC44/96 & Pieris & $\begin{array}{l}\text { No reaction to } \\
\text { hybridization } \\
\text { probes }\end{array}$ & $1,404,002$ & Rhizobium & 0 \\
\hline B131/95 & $\begin{array}{l}\text { Peach/Almon } \\
\text { d Rootstock }\end{array}$ & $\begin{array}{l}\text { Pathogenicity } \\
\text { assay }\end{array}$ & 539,283 & Agrobacterium & 46 \\
\hline B133/95 & $\begin{array}{l}\text { Peach/Almon } \\
\text { d Rootstock }\end{array}$ & $\begin{array}{l}\text { Pathogenicity } \\
\text { assay }\end{array}$ & $1,199,902$ & Agrobacterium & 46 \\
\hline B140/95 & $\begin{array}{l}\text { Peach/Almon } \\
\text { d Rootstock }\end{array}$ & $\begin{array}{l}\text { Response to } 20 \\
\text { different } \\
\text { biochemical and } \\
\text { physiological } \\
\text { tests }\end{array}$ & 448,314 & A. tumefaciens & 51 \\
\hline $\mathrm{N} 2 / 73$ & $\begin{array}{l}\text { Cranberry } \\
\text { gall }\end{array}$ & $\begin{array}{l}\text { Response to } 20 \\
\text { different } \\
\text { biochemical and } \\
\text { physiological } \\
\text { tests }\end{array}$ & $1,345,404$ & A. tumefaciens & 64 \\
\hline $\mathrm{W} 2 / 73$ & Euonymus & $\begin{array}{l}\text { Response to } 20 \\
\text { different } \\
\text { biochemical and } \\
\text { physiological } \\
\text { tests }\end{array}$ & $1,244,159$ & A. rubi & 51 \\
\hline $\begin{array}{l}15-1187- \\
1-2 a\end{array}$ & Yarrow & virD2 PCR & 508,223 & A. tumefaciens & 39 \\
\hline $\begin{array}{l}15-1187- \\
1-2 b\end{array}$ & Yarrow & virD2 PCR & 299,970 & A. tumefaciens & 38 \\
\hline $14-2641$ & Rose & No data & 698,756 & Serratia & 0 \\
\hline $15-172$ & $\begin{array}{l}\text { Leucanthemu } \\
\mathrm{m}\end{array}$ & $\begin{array}{l}\text { Colony } \\
\text { morphology on } \\
\text { selective media }\end{array}$ & 384,308 & A. tumefaciens & 56 \\
\hline $15-174$ & $\begin{array}{l}\text { Leucanthemu } \\
\mathrm{m}\end{array}$ & $\begin{array}{l}\text { Colony } \\
\text { morphology on } \\
\text { selective media }\end{array}$ & 753,570 & A. tumefaciens & 58 \\
\hline
\end{tabular}




\section{Figure $\mathbf{1}$ (on next page)}

Overview of Gall-ID diagnostic tools.

DNA sequence information can be used to reveal the identity of the causative agent (unknown isolate) of disease. Tools associated with "Gall Isolate Typing" and "Phytopathtype" use 16S rDNA or pathogen-specific MLSA gene sequences to infer the identity of the isolate by comparing the sequences to manually curated sequence databases. Tools associated with "Whole Genome Analysis" and "Vir-Search" use Illumina short sequencing reads to characterize pathogenic isolates. The former tab provides downloadable tools to infer genetic relatedness based on SNPs (WGS Pipeline) or average nucleotide identity (Auto ANI). The "Vir-Search" tab provides an on-line tool to quickly map short reads against a database of sequences of virulence genes. 
Unknown isolate ${ }^{\text {Manuscript to be reviewed }}$

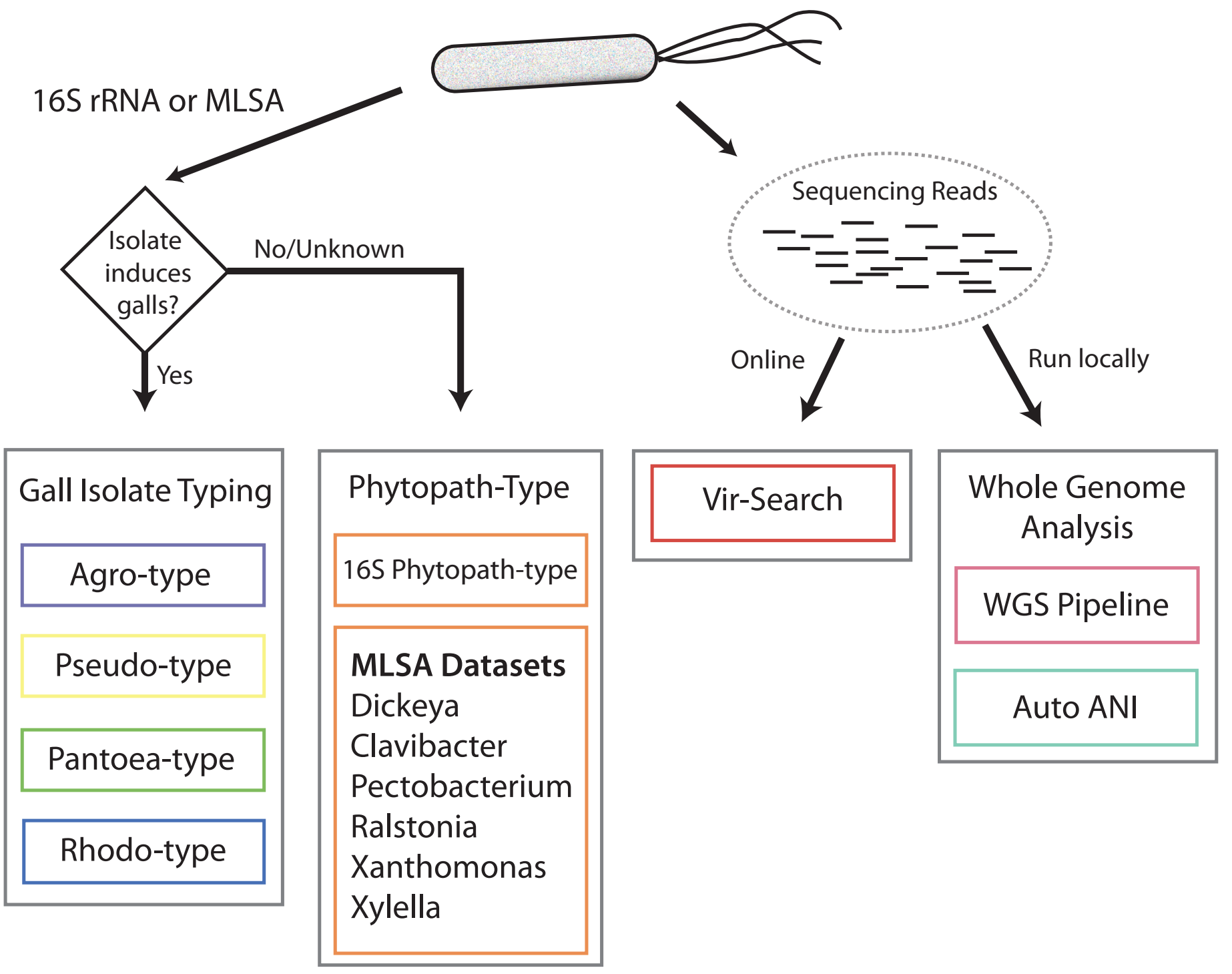




\section{Figure 2 (on next page)}

Flowchart for the WGS Pipeline.

Scripts and the programs that each script runs are boxed and presented along the left. The logic flow of the WGS Pipeline tool is presented along the right. Rectangles with rounded corners $=$ inputs and outputs; boxes outlined in red = processes. The inputs, outputs, and processes are matched to the corresponding script and program. 


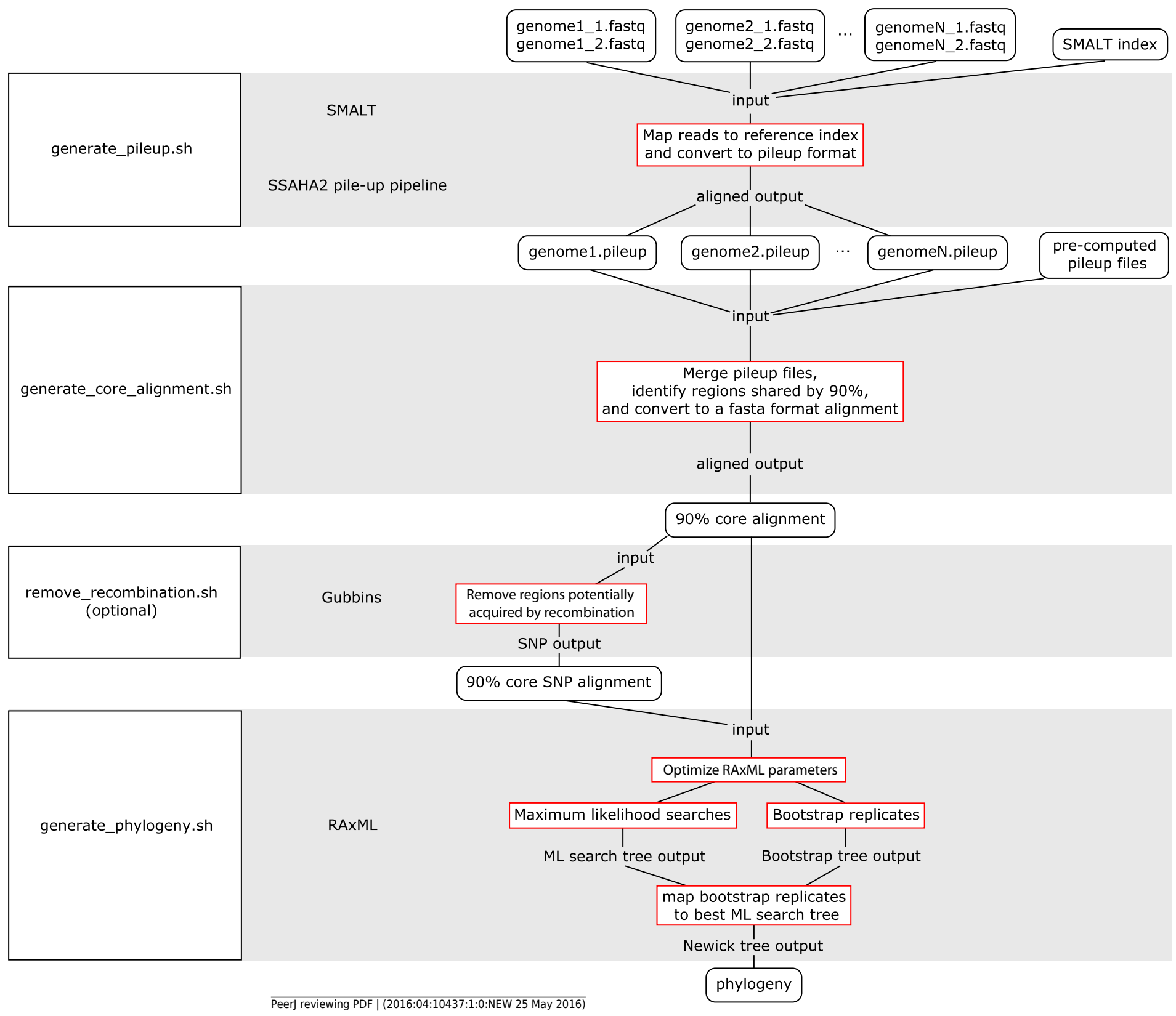




\section{Figure 3 (on next page)}

Validation of the Agro-type and Vir-Search tools.

A) An unrooted Neighbor Joining phylogenetic tree based on 16s rDNA sequences from Agrobacterium spp. The $16 \mathrm{~S}$ rDNA sequence was identified and extracted from the genome assembly of Agrobacterium isolate 13-2099-1-2 and analyzed using the tool available in the Agro-type tab. The isolate is labeled in red, as "query_isolate"; inset shows the clade that circumscribes the isolate. B) Screenshot of output results from Vir-Search. Paired 2×300 bp MiSeq short reads from Agrobacterium isolate 13-2099-1-2 were analyzed using the VirSearch tool in Gall-ID. Reference virulence gene sequences that were aligned are indicated with a green plus ("+") icon and the lengths and depths of the read coverage are reported (must exceed user-specified cutoffs, which were designated as $90 \%$ minimum coverage and $20 \%$ maximum sequence divergence). Virulence genes that failed to exceed user-specific cutoffs for read alignment parameters are indicated with a red "X". Virulence genes are grouped into categories based on their function in virulence. 
A.

B. Virulence Gene Search results

\section{Submititedio name: testitis}

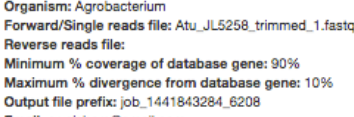

Result table

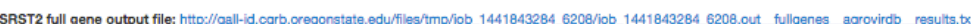

Agrobacterenium tumetaciens C58 geres were used as reference tor all virulence genes except tor GALLS which came trom Agrobacterium mizogenes strain K599

g. Agrobacterium_tumefaciens_P4 L of 4 [ Agrobacterium_tumefaciens_5A Agrobacterium_tumetaciens Agrobacterium_sp._H13-3 Agrobacterium_arsenijev 9 Agrobacterium fabrum st. Agrobacterium_tumefaciens_strain_LBA4404 A Agrobacterium_tumefaciens strain_

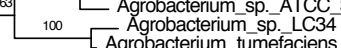
Agrobacterium_tumetaciens_strain_SUL A Agrobacterlum_sp. 224MFTSTsu3.1 ${ }^{95}$ - Agrobacterium tumetaciens GW4 40 Agrobacterium tumefaciens $\mathrm{F2} 2$ Agrobacterium_tumefaciens_strain_S2 Agrobacterium_tumefaciens_str. Cherry $2 \mathrm{E}-2-2$ [ Rhizobium_sp. IRBG74

L Rhizobium_sp. Sp. RS1a

32- Rhizobium_lupini_HPGLL

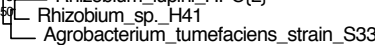

" Found Gene Coverage (\%) Depth Closest Allele

Oncogenes
Found Gene Coverage (\%) Depth Closest Allele

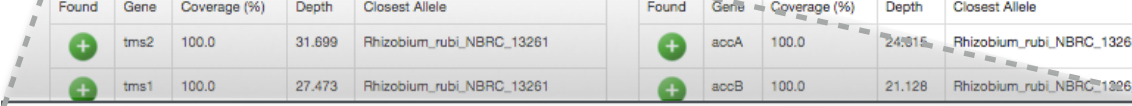

Oncogenes

\begin{tabular}{|c|c|c|c|c|c|c|c|c|c|c|}
\hline Found & & Gene & \multicolumn{2}{|c|}{ Coverage (\%) } & Depth & \multicolumn{5}{|c|}{ Closest Allele } \\
\hline & & tms2 & \multicolumn{2}{|c|}{100.0} & 31.699 & \multicolumn{5}{|c|}{ Rhizobium_rubi_NBRC_13261 } \\
\hline & & tms1 & \multicolumn{2}{|c|}{100.0} & 27.473 & \multicolumn{5}{|c|}{ Rhizobium_rubi_NBRC_13261 } \\
\hline & & ipt & \multicolumn{2}{|c|}{100.0} & 36.349 & \multicolumn{5}{|c|}{ Rhizobium_rubi_NBRC_13261 } \\
\hline & & galls & \multicolumn{2}{|l|}{-} & - & \multicolumn{5}{|l|}{-} \\
\hline Q & & & & & & + & noct & 100.0 & 26.191 & Phizobium_rubiNBAC_13261 \\
\hline+ & vire3 & 100.0 & 28.21 & \multicolumn{2}{|c|}{ BRC_13261 } & $\odot$ & nos & 100.0 & 27.164 & Rhizobium_rubi_NBAC_13261 \\
\hline$\odot$ & vire4 & 100.0 & 30.705 & \multicolumn{2}{|c|}{ Phizobium_rubi_NBRC_13261 } & $\odot$ & noxA & 100.0 & 24.153 & Rhizobium_rubi_NBAC_13261 \\
\hline$\odot$ & virB5 & 100.0 & 23.976 & \multicolumn{2}{|c|}{ Agrobacterium_arsenijevici__strain_KFB__390 } & $\oplus$ & $\operatorname{noxB}$ & 100.0 & 25.276 & Rhizobium_rubiNBBAC_13261 \\
\hline$\odot$ & virB6 & 100.0 & 31.687 & \multicolumn{2}{|c|}{ Agrobacterium_arsenij|evicii_strain_KFB_3з0 } & $\oplus$ & oocd & 100.0 & 27.164 & Rhizobium_rubi_NBAC_13261 \\
\hline$\odot$ & virB7 & 100.0 & 28.272 & \multicolumn{2}{|c|}{ Agrobacterium_arsenijievicii_strain_KFB_.330 } & $\odot$ & occm & 100.0 & 63.642 & Rhizobium_.sp._YYAO60 \\
\hline$\oplus$ & virB8 & 100.0 & 35.109 & \multicolumn{2}{|c|}{ Fhizobium_rubi_NBAC_13261 } & + & occP & 100.0 & 66.448 & Rhizobium_tropici_strain_YY530 \\
\hline$\oplus$ & vire9 & 100.0 & 27.213 & \multicolumn{2}{|c|}{ Fhizobium_ubi_NBRC_13261 } & + & 0000 & 100.0 & 59.199 & Agrobacterium_radiobacter_KeA \\
\hline$\oplus$ & vir 10 & 0 & 27.482 & \multicolumn{2}{|c|}{ Fhizobium_ubi_NBAC_13261 } & & & & & \\
\hline
\end{tabular}




\section{Figure 4 (on next page)}

Maximum likelihood tree based on vertically inherited polymorphic sites core to 20 Rhodococcus isolates.

WGS Pipeline was used to automate the processing of paired end short reads from 20 previously sequenced Rhodococcus isolates, and generate a maximum likelihood unrooted tree. Sequencing reads were aligned, using $R$. fascians strain A44a as a reference. SNPs potentially acquired via recombination were removed. The tree is midpoint-rooted. Scale bar $=0.05$ average substitutions per site; non-parametric bootstrap support as percentages are indicated for each node. Major clades and sub-clades are labeled in a manner consistent with previous labels. 


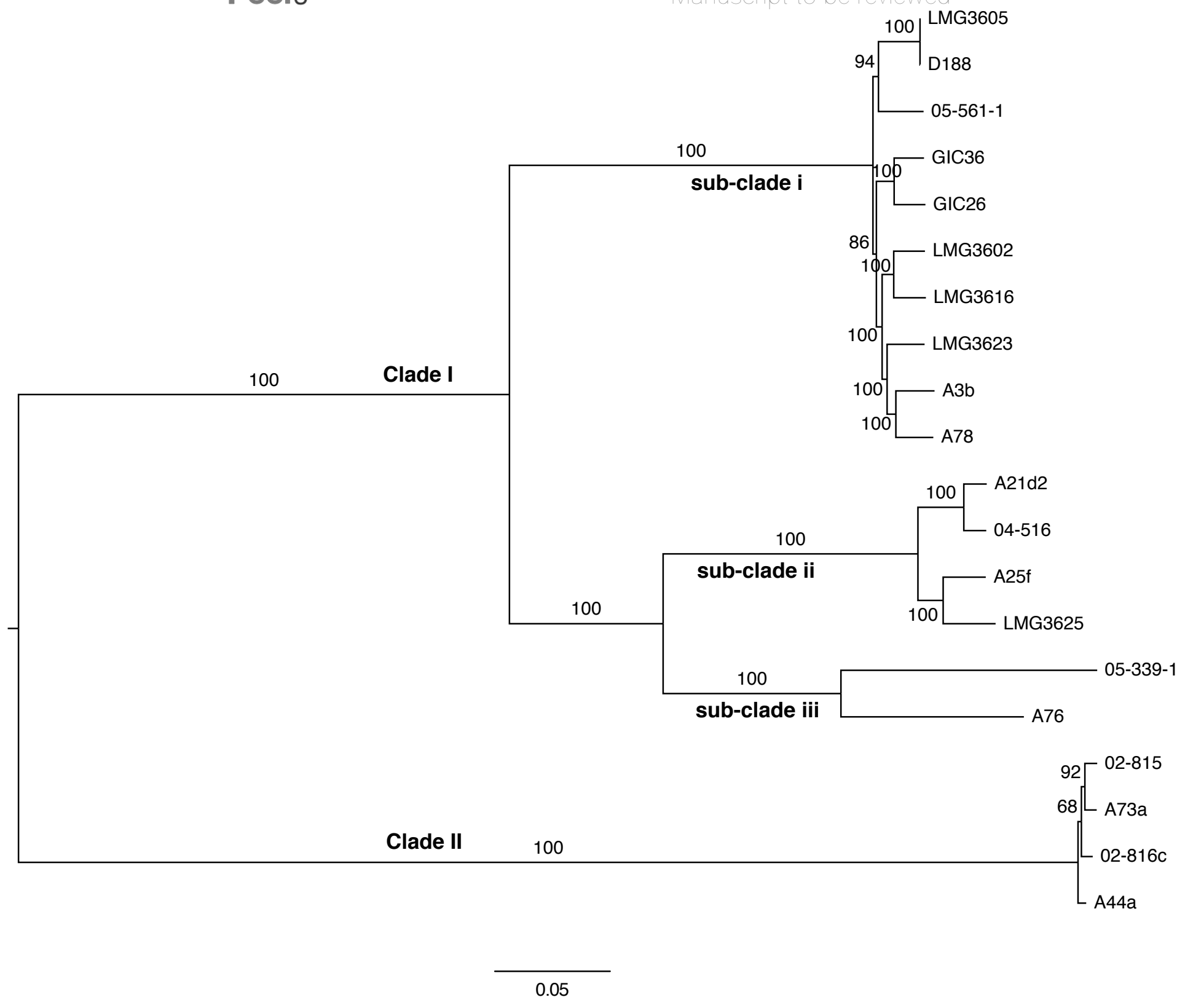

